\title{
Pyrroloquinoline Quinone Induces Cancer Cell Apoptosis via Mitochondrial-Dependent Pathway and Down-Regulating Cellular Bcl-2 Protein Expression
}

\author{
Zhihui Min ${ }^{1,2,3 *}$, Lingyan Wang ${ }^{*}$, Jianjun Jin ${ }^{1,2}$, Xiangdong Wang1,2,3, Bijun Zhu ${ }^{1}$, Hao Chen ${ }^{4},{ }^{凶}$, Yunfeng
} Cheng $1,3,5,6 \bowtie$

1. Biomedical Research Center, Zhongshan Hospital, Fudan University, Shanghai 200032, China;

2. Biomedical Research Center, Zhongshan Hospital Qingpu Branch, Shanghai, 201700 China;

3. Shanghai key laboratory of organ transplantation, Shanghai, 200032, China;

4. Department of Cardiothoracic Surgery, Tongji Hospital, Tongji University, Shanghai 200065, China;

5. Department of Hematology, Zhongshan Hospital, Fudan University, Shanghai 200032, China;

6. Department of Hematology, Zhongshan Hospital Qingpu Branch, Shanghai, 201700 China.

* These authors contributed equally to this work.

\begin{abstract}
$\square$ Corresponding author: Yunfeng Cheng, MD, PhD. Department of Hematology, Biomedical Research Center, Zhongshan Hospital, Fudan University, 180 Fenglin Rd, Shanghai 200032, China. Email: yfcheng@fudan.edu.cn Hao Chen, MD, PhD. Department of Cardiothoracic Surgery, Tongji Hospital, Tongji University, 389 Xincun Rd, Shanghai 200065, China. Email: h.chen@fudan.edu.cn Tel: +86-21- 64041990 ext. 2295 Fax: +86-21-64041990 ext. 2295.
\end{abstract}

(c) Ivyspring International Publisher. This is an open-access article distributed under the terms of the Creative Commons License (http://creativecommons.org/ licenses/by-nc-nd/3.0/). Reproduction is permitted for personal, noncommercial use, provided that the article is in whole, unmodified, and properly cited.

Received: 2014.03.03; Accepted: 2014.06.16; Published: 2014.07.29

\begin{abstract}
Pyrroloquinoline quinone (PQQ) has been reported as a promising agent that might contribute to tumor cell apoptosis and death, yet little is known on its mechanisms. In current study, the effect of PQQ on cell proliferation and mitochondrial-dependent apoptosis were examined in 3 solid tumor cell lines (A549, Neuro-2A and HCC-LM3). PQQ treatment at low to medium dosage exhibited potent anti-tumor activity on A549 and Neuro-2A cells, while had comparably minimal impact on the viabilities of 2 human normal cell lines (HRPTEpiC and HUVEC). The apoptosis of the 3 tumor cell lines induced by PQQ were increased in a concentration-dependent manner, which might be attributed to the accumulation of intracellular reactive oxygen species (ROS), decline in ATP levels and dissipation of mitochondrial membrane potential (MMP), in conjunction with down-regulation of $\mathrm{Bcl}-2$ protein expression, up-regulation of activated caspase-3, and disturbed phosphorylated MAPK protein levels. PQQ induced tumor cells apoptosis was significantly alleviated by pan-caspase inhibitor Z-VAD-FMK. The present work highlights the potential capability of PQQ as an anti-tumor agent with low toxicity towards normal cells through activating mitochondrial-dependent apoptosis pathways, and warrants its development for cancer therapy.
\end{abstract}

Key words: pyrroloquinoline quinone (PQQ); apoptosis; MAPK; mitochondrial membrane potential; bcl-2.

\section{Introduction}

Pyrroloquinoline quinone (PQQ) was primarily identified in methylotrophic bacteria as a novel bacterial enzymatic cofactor [1] and was considered to be a new B group of vitamins [2]. As an essential nutri- ent, PQQ is a water-soluble and thermal stable small molecular organic matter, exists in various plant and animal cells, at $\mathrm{pM}$ to $\mathrm{nM}$ levels $[3,4]$. Researches of PQQ have been focused on its activities as an antiox- 
idant and redox modulator[5], cardio- and neuro-protectant $[6,7]$, and its radioprotective effects on hemopoietic system [8].

Recently, studies showed that PQQ could induce apoptosis in human promonocytic leukemia U937 and lymphoma EL-4 cells, as well as Jurkat cell programmed death [5]. The underlying mechanism might be relevant to the increase of intracellular reactive oxygen species (ROS) and depletion of glutathione [9]. Another study in vivo indicated that at nanoto micro-mole levels of PQQ intake in animal diets could affect the cell signaling, especially activation of MAPK-related families and JAK/STAT3 signaling in the livers of rat [10]. In addition, PI3K/Akt, ras-related ERK1/2 [7] and phosphorylation of JNK signaling pathways were proved to be associated with the neuro-protective effect of PQQ in hippocampal neurons [11].

These findings suggested that PQQ not only regulates redox status of the cells, but also poses impact on the cellular signaling pathways. However, to date, there is no study that has investigated the effect of PQQ on directly inducing solid tumor cell apoptosis except for the hematological tumors $[5,9]$. The underlying molecular mechanism of PQQ's anticancer effect remains to be elucidated. Inasmuch, this work aimed to determine whether PQQ has apoptosis-inducing effect in solid tumor cells, and to explore the potential mechanisms.

\section{Materials and methods}

\section{Chemicals and cell lines}

Pyrroloquinoline quinine (PQQ) was obtained from Changmao Biochemical Engineering Co., LTD (Changzhou, China). PQQ stock solution (10mM) was prepared in DMEM medium, stored in $-20^{\circ} \mathrm{C}$. Benzyloxycarbonyl-Val-Ala-Asp (OMe) fluoromethylketone (Z-VAD-FMK) was acquired from Enzo Life Sciences, Inc (Lausen, Switzerland). A549 (human non-small cell lung adenocarcinoma) and Neuro-2A (mouse neuroblastoma) cell lines were purchased from the cell bank of Chinese Academy of Sciences (Shanghai, China). HRPTEpiC (human renal proximal tubular epithelial cells) was purchased from ScienCell research laboratories (Carlsbad, California, USA). HUVEC (human umbilical vein endothelial cells) and HCC-LM3 (human hepatocellular carcinoma) cell lines were kindly provided by the Liver Cancer Research Institute of Zhongshan Hospital, Fudan University (Shanghai, China), and maintained on the basis of ATCC guidelines at our center. All cells were cultured in Dulbecco's modified Eagle's medium (DMEM/High Glucose, Thermo Scientific HyClone,
Logan, Utah, USA) containing $10 \%$ fetal bovine serum (FBS), 1\% (v/v) penicillin-streptomycin (Gibco Invitrogen, Grand Island, NY, USA) at $37^{\circ} \mathrm{C}$ in a humidified atmosphere with $5 \% \mathrm{CO}_{2}$. Cells were treated for up to $48 \mathrm{~h}$ with PQQ at designated concentrations, another cell culture without PQQ treatment was served as control.

\section{Cell bio-behaviors assay with a continuous cell culturing platform (CELL-IQ)}

The cell bio-behaviors including total cell number, cell differentiation and cell movement were measured by a real-time cell monitoring system, Cell-IQ cell culturing platform (Chip-Man Technologies, Tampere, Finland), equipped with a phase-contrast microscope (Nikon CFI Achromat phase contrast objective with $10 \times$ magnification). The equipment was controlled by Cell-IQ image software (Chip-Man Technologies). Analysis was carried out with a freely distributed Image software (McMaster Biophotonics Facility, Hamilton, ON, Canada), using the Manual Tracking plugin created by Fabrice Cordeliéres (Institut Curie, Orsay, France). Cell-IQ system uses machine vision technology for monitoring and recording time-lapse data, and it can also analyze and quantify cell functions and morphological parameters [12]. This system was used to discriminate cell stage (dividing/stable stage) and calculate cell numbers of each stage during proliferation. Besides, Cell-IQ was programmed to quantify the movement of each individual cell in the image field. The distance of total cell movement indicates the high migratory intention of cancer cells.

In the current study, cells treated with PQQ at different concentrations were cultured in Cell-IQ system with 24 -well plates $\left(8 \times 10^{3}\right.$ cells /well $)$ for up to $48 \mathrm{~h}$. Images were captured at $5 \mathrm{~min}$ intervals for up to 48h. Cell stages, total cell number, cell differentiation and cell movement were then automatically analyzed.

\section{Cell viability assay}

The cell viability of PQQ was evaluated using Cell Counting Kit-8 (CCK-8) assay (Dojindo Laboratories, Kumamoto, Japan), per instruction of the manufacturer. In brief, cells were seeded in 96-well plates at $1 \times 10^{4}$ cells/well and allowed an overnight period for attachment. After treatment for $48 \mathrm{~h}$ with PQQ at serial concentrations, CCK-8 solution (10 $\mu \mathrm{l})$ was added to each well, followed by $3 \mathrm{~h}$ of incubation at $37^{\circ} \mathrm{C}$. The absorbance wavelength at $450 \mathrm{~nm}$ was recorded for each well in a FlexStation 3 microplate reader (Molecular Devices, Sunnyvale, California, USA), and cell viability was then accessed according to the manufacturer instruction. 


\section{Detection of apoptosis with Annexin V-FITC/PI staining}

Cell apoptosis was determined by the Annexin V-fluorescein isothiocyanate (FITC)/Propidium Iodide (PI) Apoptosis Detection Kit (EMD Biosciences, La Jolla, USA). Cells were cultured in 24-well plate at a density of $5 \times 10^{4}$ cells $/ \mathrm{ml}$ and treated with PQQ for 24h. Cells were harvested and resuspended in binding buffer, and then stained with $2.5 \mu$ Annexin V-FITC and $5 \mu \mathrm{l}$ propidium iodide (PI), and incubated for 15 min at room temperature in the dark. The stained cells were detected within 30 minutes with BD FACS Aria II flow cytometer (BD biosciences, San Jose, California, USA).

\section{Reactive oxygen species (ROS) measurement}

The intracellular ROS levels of 3 tumor cells were measured by reactive oxygen species assay kit (Beyotime Institute of Biotechnology, Shanghai, China). Briefly, cells were seeded in 6-well plates $\left(1 \times 10^{5}\right.$ cells/well) followed by overnight incubation and treatment with indicated concentration of PQQ for additional $4 \mathrm{~h}, 12 \mathrm{~h}$ and $24 \mathrm{~h}$. Cells were then trypsinized and washed with PBS buffer before loading with $5 \mu \mathrm{M}$ fluorescent probe 2', 7'-dichlorodihydrofluorescein diacetate $\left(\mathrm{H}_{2} \mathrm{DCFDA}\right)$ at $37^{\circ} \mathrm{C}$ for 30 minutes in dark. The fluorescent intensity was analyzed with flow cytometer (FACS Aria II, BD biosciences).

\section{Cellular ATP release assay}

Cells were cultured in the 96-well plates with 100 $\mu \mathrm{l}$ medium per well. After treatment with different concentrations of PQQ for $4 \mathrm{~h}, 12 \mathrm{~h}$, and 24h, CellTiter-Glo Reagent (Promega, Madison, Wisconsin, USA) was added to each well for the plate. The reagent and culture medium were mixed for 2 minutes on an orbital shaker and the optical density (O.D.) was measured using a microplate reader (Flexstation3, Molecular Devices). All experiments were done in triplicate and repeated three times independently.

\section{Detection of active caspase-3}

Cells were treated with PQQ for $24 \mathrm{~h}$ on the indicated concentrations, and collected, followed by cells were fixating, permeabilizating and intracellular staining with anti-active Caspase-3 V450 antibody (BD biosciences), according to the manufacturer's instructions. The activity of caspase- 3 was presented as mean fluorescent intensity of cells and performed by flow cytometer (BD FACS Aria II).

\section{Cell cycle analysis}

After PQQ treatment, cells were harvested for cell cycle phase distributions detected by BD LSR
Fortessa flow cytometry (BD biosciences). Stained cells were tested on flow cytometer according to the instructions of Cycle Test ${ }^{\mathrm{TM}}$ Plus DNA Reagent Kit (BD biosciences), and then analyzed using Flowjo software version 7.6.2. (Tritar Inc., San Carlos, California, USA).

\section{Measurement of Mitochondrial Membrane Potential}

Mitochondrial membrane potential was assessed using the fluorescent probe JC-1 (MitoProbe ${ }^{\mathrm{TM}}$, Invitrogen, Grand Island, NewYork, USA), which was a cationic dye that displayed potential-dependent accumulation and normal formation of red fluorescent J-aggregates in mitochondria, indicated by a fluorescence emission shift from green $(\sim 529 \mathrm{~nm})$ to red $(\sim 590 \mathrm{~nm})$. A green fluorescent (JC-1 as a monomer at low membrane potentials) and a red fluorescent (JC-1 as "J-aggregates" at higher membrane potentials) were monitored under flow cytometer (BD FACS Aria II). Samples treated with Carbonyl cyanide m-chlorophenylhydrazone (CCCP), a mitochondrial uncoupling agent, were used as positive-control to perform standard compensation. Consequently, depolarization of mitochondrial membrane potential is indicated by a decrease in the red/green fluorescence intensity ratio. Cells were suspended in $1 \mathrm{ml}$ PBS at approximately $1 \times 10^{6}$ cells $/ \mathrm{ml}$ for each sample. For the positive-control tube, added $1 \mu \mathrm{l}$ of $50 \mathrm{mM}$ CCCP and incubated the cells at $37^{\circ} \mathrm{C}$ for $5 \mathrm{~min}$. The sample cells were incubated at $37^{\circ} \mathrm{C}$ for $20 \mathrm{~min}$ with $2 \mu \mathrm{M}$ JC-1, then washed once with $2 \mathrm{ml}$ PBS and placed in $500 \mu 1$ PBS until analyzed by flow cytometer.

\section{Measurement of Bcl-2, ERK2, MEK2, pERKI/2 and P38MAPK proteins}

To investigate the underlying mechanisms of apoptosis induced by PQQ, we tested the effect of PQQ on key signaling pathway proteins in A549 and neuro-2A cells. These 2 cell lines were treated with $15-360 \mu \mathrm{M}$ of PQQ for $24 \mathrm{~h}$. The expression levels of Bcl-2, ERK2, MEK2, pERK1/2 and p38 MAPK were analyzed by flow cytometer and presented as mean fluorescent intensity (MFI). In brief, cells were seeded in 24-well plates and treated with designated concentrations of PQQ for $24 \mathrm{~h}$. After $24 \mathrm{~h}$ culture, cells were fixed and permeabilized (BD CytofixTM Fixation Buffer Cat. No. 554655, and Phosflow Perm Buffer III, Cat. No. 558050, BD biosciences), and intracellularly stained with anti-Human Bcl-2 FITC (BD biosciences), anti-ERK2 Alexa Fluor 488, anti-MEK2 PE, anti-pERK1/2 pT202/pY204 PerCP-Cy5.5, anti-p38 MAPK pT180/pY182 PE-Cy7 (Phosflow, BD biosciences) according to the manufacturer's instructions. The expression levels were tested on BD FACS Aria II 
flow cytometer and then analyzed using Flowjo software version 7.6.2.

\section{Statistical analysis}

All analyses were performed with SPSS software version 13.0 (SPSS Inc., Chicago, USA). Data were expressed as mean \pm SEM. Normality was assessed by Shapiro-Wilk $W$ test. Student $t$ test and Wilcoxon rank-sum (Mann-Whitney) test were used for data fulfilled normal distribution and for those did not, respectively. When multiple groups were compared, One Way ANOVA and Kruskal Wallis test were used for data fulfilled normal distribution and for those did not, respectively. Two-sided $p$ values less than 0.05 were considered statistically significant.

\section{Results}

\section{The proliferation of cancer cell lines suppressed by PQQ}

The cells were seeded in 24-well plates $\left(3 \times 10^{4}\right.$ cells per well) overnight and then treated with PQQ at different concentrations respectively or without PQQ treatment (control group). As shown in Figure $1 \mathrm{~A}$ and $1 \mathrm{~B}$, the cell growth curve generated by Cell-IQ monitoring system displayed notably inhibitory effects of PQQ in a dose- and time-dependent manner on treated A549 and Neuro-2A cells, with $\mathrm{IC}_{50}$ at $24 \mathrm{~h}$ of $50.16 \mu \mathrm{M}$ and $56.21 \mu \mathrm{M}$, respectively. Compared with the control group, the proliferation inhibitory effects of PQQ were significant at $24 \mathrm{~h}$ and $48 \mathrm{~h}$ in both cell lines. The inhibitory effects were significant from 30 $\mu \mathrm{M}$ to $600 \mu \mathrm{M}$ in A549 cells, and from $30 \mu \mathrm{M}$ to 360 $\mu \mathrm{M}$ in Neuro-2A cells overtime. Therefore, we chose the time-point of $24 \mathrm{~h}$ at low $(15-30 \mu \mathrm{M})$, medium $\left(\mathrm{IC}_{50}\right)(60-75 \mu \mathrm{M})$ and high $(120-300 \mu \mathrm{M})$ concentrations for further studies. There were no significant inhibitory effects observed on HCC-LM3 cells proliferation at $15-150 \mu \mathrm{M}$ comparing with the control group, the $\mathrm{IC}_{50}$ at $24 \mathrm{~h}$ was more than $300 \mu \mathrm{M}$. However, higher dose PQQ treatments $(300-1200 \mu \mathrm{M})$ inhibited the proliferation of HCC-LM3 cells (Figure 1C).

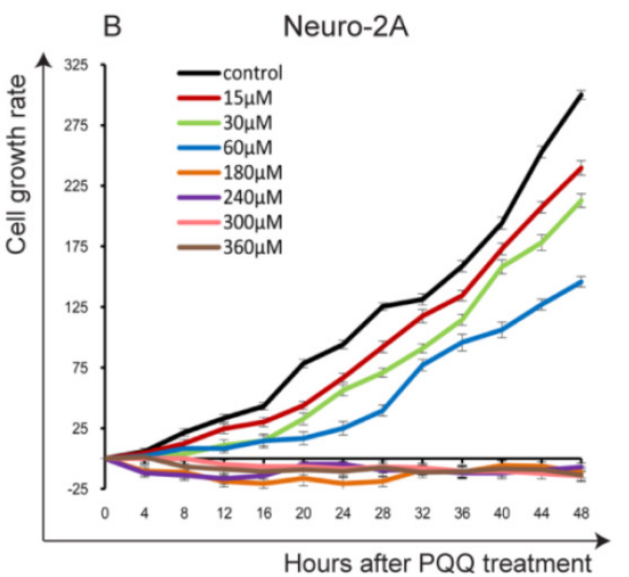

LM3
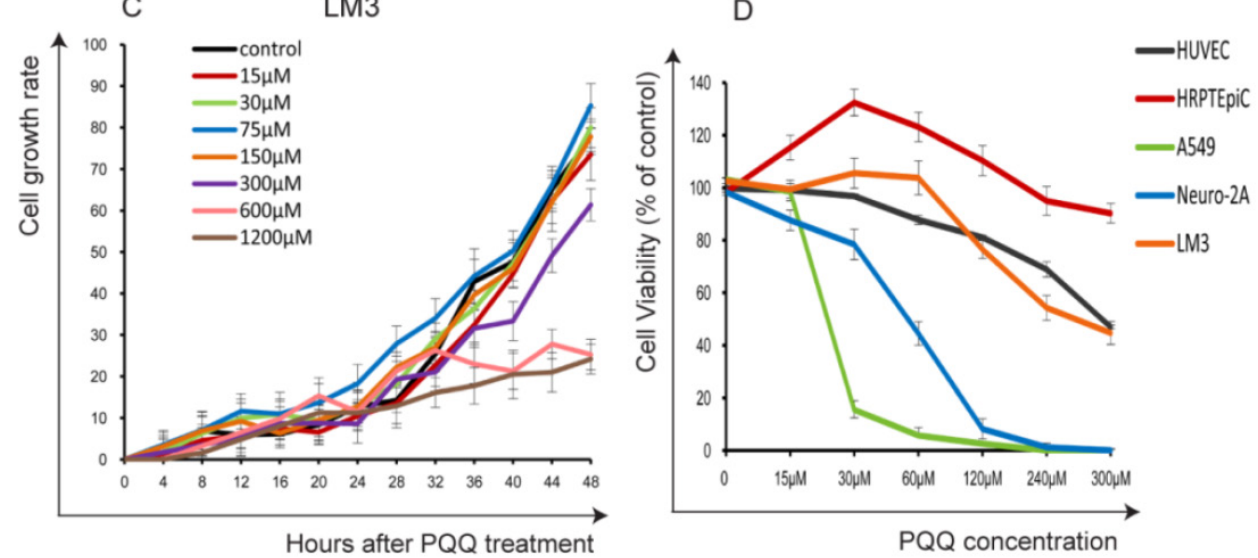

Figure I. The cells proliferation and viability. PQQ inhibited proliferations of 3 cancer cell lines for up to $48 \mathrm{~h}$ were measured by Cell-IQ assay. Cell number of each microscopic field at different time points was imaged and counted. Data obtained from nine different microscopic fields in each group were showed with mean \pm SEM and error bar for A549 cells (panel A), Neuro-2A cells (panel B) and HCC-LM3 cells (panel C). Panel D illustrates the viability of the 3 cancer cells and 2 normal cells (HRPTEpiC, HUVEC) assessed by CCK-8 assay after PQQ treatment for $48 \mathrm{~h}$. 
In order to evaluate the possible cytotoxicity of PQQ to normal cells, we also examined 2 normal cell lines (HRPTEpiC and HUVEC). Cell viability was determined by the CCK-8 assay. Under the same conditions, these 2 cell lines were exposed to various concentrations of PQQ $(0-300 \mu \mathrm{M})$ for $48 \mathrm{~h}$. As shown in Figure 1D, HRPTEpiC cells maintained excellent viability after incubation with $0-300 \mu \mathrm{M}$ of PQQ for 48h. HUVEC cells maintained good viability (100\%-80\% comparing to the control) until PQQ concentration reached $240-300 \mu \mathrm{M}$. In contrast, the viabilities of A549 and Neuro-2A cells were remarkably compromised in a dose-dependent manner, began at $30 \mu \mathrm{M}$ and became significant from $60 \mu \mathrm{M}$ of PQQ. In consistent with the Cell-IQ results, the reduced viabilities of HCC-LM3 cells were only observed at higher concentrations $(240-300 \mu \mathrm{M})$.

Images of each microscopic field were captured every 20-minute for 48 hours. Cell-IQ system automatically calculated total cell number of each image by specialized software. As shown in Figure 2, treatment with PQQ at 30-300 $\mu \mathrm{M}$ displayed typical poor growth and apoptosis morphological changes such as membrane blebbing, cellular shrinkage and chromatin condensation in A549 and Neuro-2A cells in a doseand time-dependent pattern, whereas the cells of the control group proliferated rapidly and reached sufficient confluence. Apoptosis changes were also observed in HCC-LM3 cells at higher doses (300-600 $\mu \mathrm{M})$ of PQQ overtime. These data indicated that A549 and Neuro-2A cells are sensitive to PQQ treatment, while HCC-LM3 cells response to higher concentrations of PQQ. Therefore, some of the subsequent studies were selectively focused on A549 and Neuro-2A cells.

\section{Apoptosis of cancer cell lines induced by PQQ}

Apoptosis of A549, Neuro-2A and HCC-LM3 cells was measured by flow cytometry analysis after treatment with PQQ at different concentrations for $24 \mathrm{~h}$. Increase in cellular surface staining with Annexin V-FITC serves as a marker for early apoptosis while staining with PI indicates loss of cell membrane integrity. A cell-permeable, irreversible pan-caspase inhibitor, Z-VAD-FMK, was used to block caspase activation of apoptotic cells. After $24 \mathrm{~h}$ treatment with PQQ, the percentage of apoptosis in A549 cells were significantly increased when compared to the control $(7.45 \pm 0.45 \%$ at $30 \mu \mathrm{M}, 12.80 \pm 0.38 \%$ at $75 \mu \mathrm{M}, 17.88 \pm$ $0.68 \%$ at $150 \mu \mathrm{M}, 37.65 \pm 0.68 \%$ at $300 \mu \mathrm{M}$, and $80.87 \pm$ $0.95 \%$ at $600 \mu \mathrm{M}$, vs $3.12 \pm 0.20 \%$ of control, $p<0.01$ respectively) (Figures $3 \mathrm{~A}$ and $3 \mathrm{C}$ ). The percentage of apoptosis in Neuro-2A cells were also significantly increased in dose-dependent pattern $(11.69 \pm 0.47 \%$ at $30 \mu \mathrm{M}, 12.62 \pm 0.56 \%$ at $60 \mu \mathrm{M}, 47.75 \pm 1.16 \%$ at 120 $\mu \mathrm{M}, 65.13 \pm 1.05 \%$ at $180 \mu \mathrm{M}, 83.15 \pm 0.80 \%$ at $300 \mu \mathrm{M}$, and $86.92 \pm 1.42 \%$ at $360 \mu \mathrm{M}$, vs $4.15 \pm 0.44 \%$ of the control, $p<0.01$, respectively) (Figures 3D and 3F). As shown in Figures $3 \mathrm{~B}$ and $3 \mathrm{C}$, been pretreated for $3 \mathrm{~h}$ with $10 \mu \mathrm{M}$ of Z-VAD-FMK prior to the indicated PQQ treatment, the percentages of apoptosis of A549 cells were significantly reduced (2-fold change) when compared with the corresponding cells that were not pretreated $(3.28 \pm 0.52 \%$ vs $7.45 \pm 0.45 \%$ at $30 \mu \mathrm{M}$, and $17.38 \pm 3.46 \%$ vs $37.65 \pm 0.68 \%$ at $300 \mu \mathrm{M}, p<0.05$, respectively). Comparing to the corresponding untreated cells, the percentages of apoptosis of Z-VAD-FMK pretreated Neuro-2A cells were similarly decreased $(8.33 \pm 0.61 \%$ vs $11.69 \pm 0.47 \%$ at 30 $\mu \mathrm{M}, 40.79 \pm 4.03 \%$ vs $83.15 \pm 0.80 \%$ at $300 \mu \mathrm{M}, p<0.05$, respectively, Figures $3 \mathrm{E}$ and $3 \mathrm{~F}$ ).

After PQQ treatment at different concentrations for $24 \mathrm{~h}$, the percentages of apoptosis HCC-LM3 cells were gradually increased from $4.92 \pm 0.28 \%(30 \mu \mathrm{M})$ to $11.18 \pm 0.21 \%(300 \mu \mathrm{M})$ and $21.05 \pm 0.92 \%(1200 \mu \mathrm{M})$ in a dose-dependent manner, compared to the negative control $(1.60 \pm 0.35 \%, p<0.01$, respectively). (Figures $3 \mathrm{G}$ and $3 \mathrm{I})$. When compared with the corresponding untreated cells, the percentages of apoptosis of Z-VAD-FMK pretreated HCC-LM3 cells were decreased $(2.71 \pm 0.55 \%$ vs $4.92 \pm 0.28 \%$ at $30 \mu \mathrm{M}$, and $7.80 \pm 1.21 \%$ vs $10.81 \pm 0.53 \%$ at $600 \mu \mathrm{M}, p<0.05$, respectively, Figures $3 \mathrm{H}$ and $3 \mathrm{I}$ ).

\section{Increased reactive oxygen species after PQQ treatment}

The generation of intracellular ROS was quantitatively analyzed by flow cytometer using $\mathrm{H}_{2}$ DCFDA dye after $4 \mathrm{~h}, 12 \mathrm{~h}$, and $24 \mathrm{~h}$ of PQQ treatment. In addition, separate cell cultures were treated with $500 \mu \mathrm{M}$ of $\mathrm{H}_{2} \mathrm{O}_{2}$ (hydrogen peroxide) 15 minutes prior to the assessment (positive controls). PQQ treatment resulted in a time- and concentration-dependent ROS accumulation in A549 and HCC-LM3 cells compared with the negative controls. Significantly increased ROS generation were observed at $4 \mathrm{~h}$ and maintained at a high level through $24 \mathrm{~h}$ in most of the concentration groups $(p<0.01$ compared to the corresponding controls, Figures $4 \mathrm{~A}$ and $4 \mathrm{C}$ ). While A549 cells exhibited a rapid and sustained generation of ROS, the accumulation of ROS in HCC-LM3 cells was a relatively mild process. In contrast, although the production of ROS in Neuro-2A cells was also significantly enhanced in most of the concentration groups $(p<0.01$ compared to the corresponding controls, Figure 4B), this effect reached peak at $12 \mathrm{~h}$.

\section{PQQ treatment reduced cellular ATP release}

ATP release levels of all the 3 tumor cell lines decreased in the presence of PQQ in a dose and time 
dependent manner. In particular, a perfect dose dependent trend was presented in A549 cells with PQQ treatment at $24 \mathrm{~h}$ (Figure 5A). Compared with the control, the reduction of ATP was $27 \%$ at $75 \mu \mathrm{M}$, and $80 \%$ at $300 \mu \mathrm{M}(19967.7 \pm 2724.2$ vs $27463.7 \pm 1588.4$ at 75 $\mu \mathrm{M}, p<0.05 ; 17914.7 \pm 1982.0$ vs $27463.7 \pm 1588.4$ at 150 $\mu \mathrm{M}, p<0.05$; and $5542.4 \pm 2407.7$ vs $27463.7 \pm 1588.4$ at $300 \mu \mathrm{M}, p<0.01)$. Compared with the control, in Neuro-2A cells with $24 \mathrm{~h}$ PQQ treatment, the reduc- tion of ATP was significant when PQQ dose was 120 $\mu \mathrm{M}$ and above $(1359.3 \pm 237.3$ vs $10559.2 \pm 1522.8$ at 120 $\mu \mathrm{M}, p<0.01 ; 836.3 \pm 184.7$ vs $10559.2 \pm 1522.8$ at $180 \mu \mathrm{M}$, $p<0.01 ; 695.8 \pm 52.3$ vs $10559.2 \pm 1522.8$ at $300 \mu \mathrm{M}, p<$ 0.01) (Figure 5B). Again, HCC-LM3 cells responded to higher concentrations of PQQ at $24 \mathrm{~h}(7490.2 \pm 103.5$ vs $10585.4 \pm 817.2$ at $300 \mu \mathrm{M}, p<0.05$; PQQ $v$ s control, $3367.8 \pm 587.1$ vs $10585.4 \pm 817.2$ at $600 \mu \mathrm{M}, p<0.01)$ (Figure 5C).
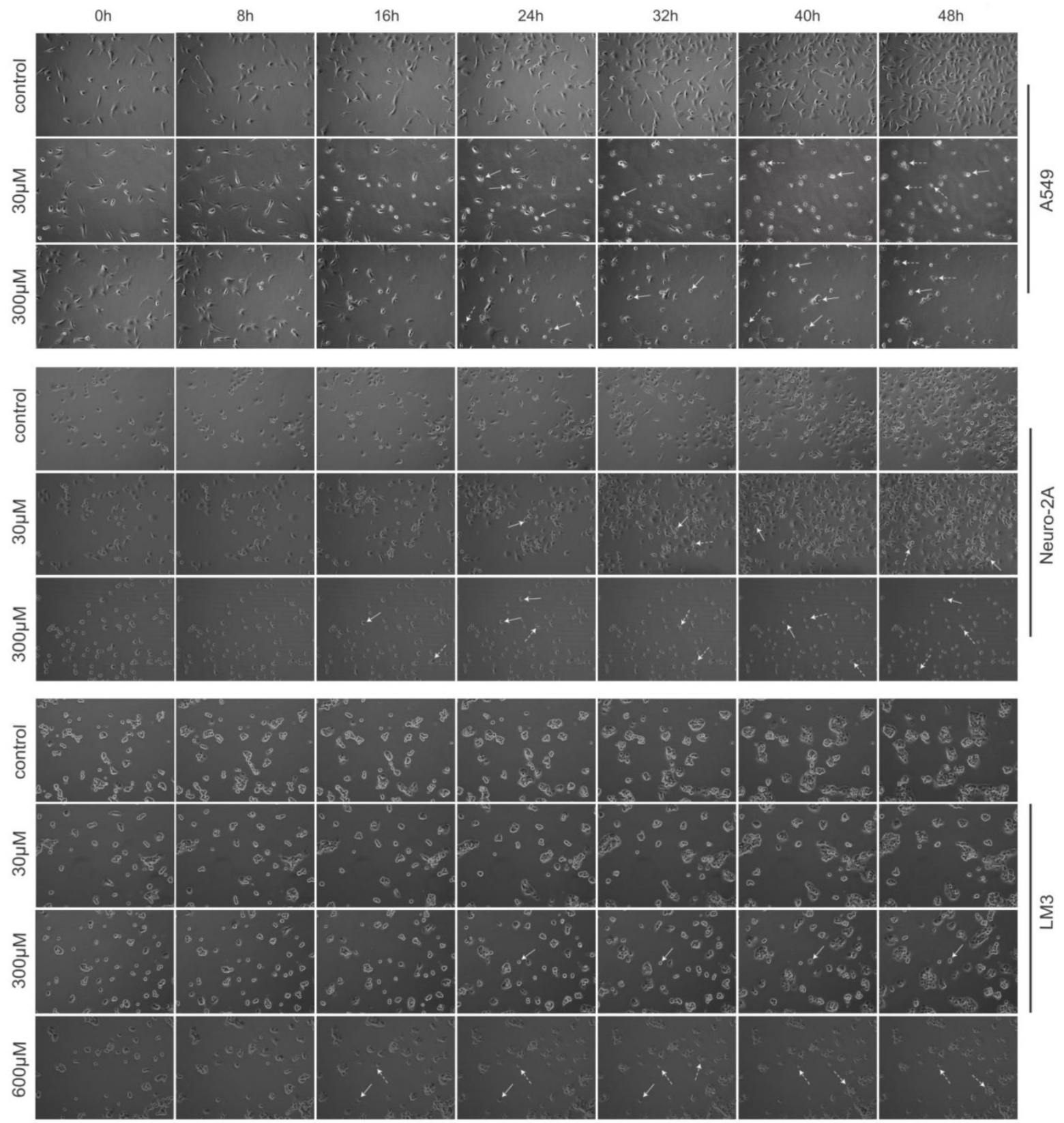

Figure 2. Morphological changes induced by PQQ. PQQ inhibited the growth of A549, Neuro-2A and HCC-LM3 cells measured by real time Cell-IQ cell culture platform. The 3 cell lines were seeded in 24 -well plates $\left(8 \times 10^{3}\right.$ cells per well) overnight and then treated with PQQ at different concentrations respectively or without PQQ (control). Cell proliferation in the given microscopic field was continuously photographed at 20-minute intervals for 48h (magnification I00x). White arrows represent chromatin condensation and dotted arrows indicate membrane blebbing. 
Figure 3. Apoptosis induced by PQQ. Treatment with $\mathrm{PQQ}$ caused dose-dependent apoptosis in 3 tumor cell lines for 24h. Early and late apoptosis were detected using Annexin V-FITC/PI-double staining analyzed by flow cytometry. Involvement of the caspase apoptosis pathway was confirmed using pan-caspase inhibitor Z-VAD-FMK pretreatment for $3 \mathrm{~h}$ prior to the indicated $\mathrm{PQQ}$ treatment. The percentage of cells was described in each quadrant. The values represent the mean \pm SEM of at least 3 independent experiments. PQQ induced apoptosis in A549 cells in dose-dependent manner, and Z-VAD-FMK markedly reduced the apoptosis (panels A, B and C). PQQ induced apoptosis in Neuro-2A cells in dose-dependent manner, and Z-VAD-FMK noticeably reduced the apoptosis (panels D, E and F). HCC-LM3 cells manifested the similar trend as well (panels $\mathrm{G}, \mathrm{H}$ and I). $* * \mathrm{p}<0.0 \mathrm{I}$ as compared with control group; $* p<0.05$ as compared with $\mathrm{PQQ}$ treatment group.
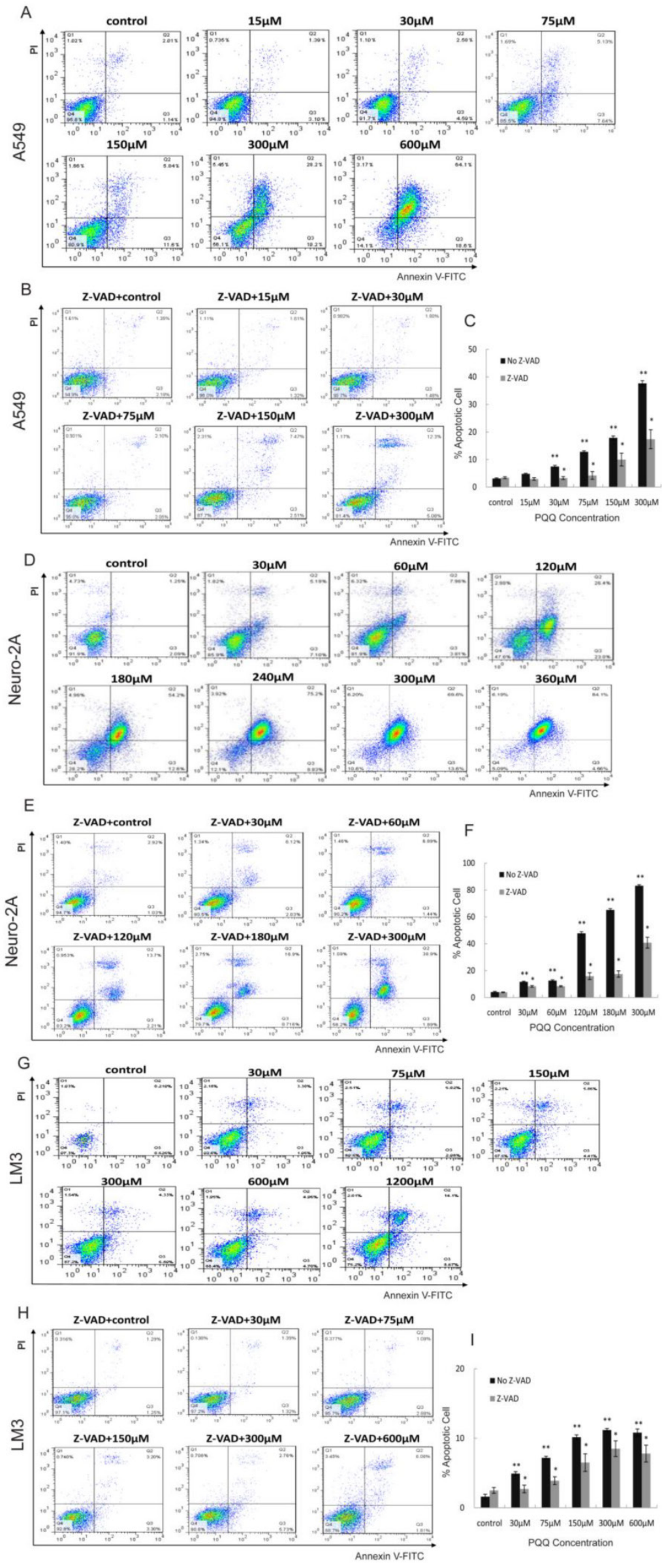


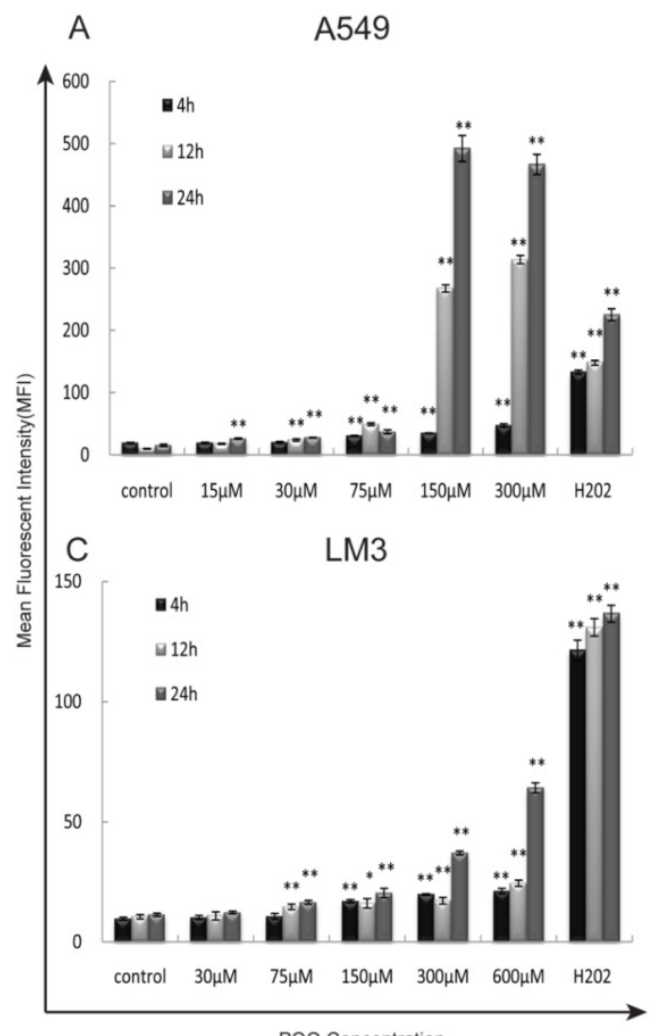

B

Neuro-2A

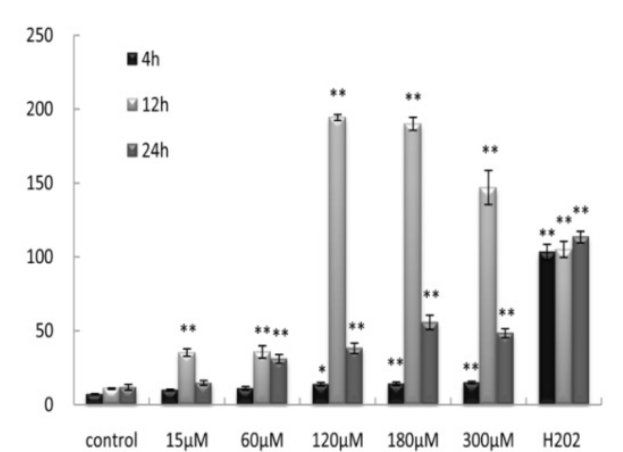

control $\quad 15 \mu \mathrm{M} \quad 60 \mu \mathrm{M} \quad 120 \mu \mathrm{M} \quad 180 \mu \mathrm{M} \quad 300 \mu \mathrm{M} \quad \mathrm{H} 202$
Figure 4. Exposure to $\mathrm{PQQ}$ triggers intracellular ROS accumulation. Three cancer cell lines, A549 cells (panel A), Neuro-2A cells (panel B) and HCC-LM3 cells (panel C) were exposed to different doses of PQQ at $4 \mathrm{~h}, 12 \mathrm{~h}$ and $24 \mathrm{~h}$. The generation of ROS was quantitatively measured by the flow

cytometer using $\mathrm{H}_{2}$ DCFDA dye. Separate cell cultures treated with $500 \mu \mathrm{M}$ of $\mathrm{H}_{2} \mathrm{O}_{2} \quad \mathrm{I} 5$ minutes prior to the assessment were used as positive controls. All values are showed as means \pm SEM from three-independent experiments. ${ }^{*} p<0.05$ as compared with control group; $*^{*} p<0.01$ as compared with control group.

PQQ Concentration

Figure 5. Reduced cell ATP levels by PQQ treatment. The intracellular ATP level in A549 cells (panel A), Neuro-2A cells (panel B) and HCC-LM3 cells (panel C) in the presence of different doses of PQQ at $4 \mathrm{~h}$, $12 \mathrm{~h}$ and $24 \mathrm{~h}$. Quantitative analysis recorded the optical density (O.D.) values of cellular ATP that were reduced when exposed to $\mathrm{PQQ}$. All values are showed as means \pm SEM from three-independent experiments. $*_{p}<0.05$ as compared with control group; $* * p<0.01$ as compared with control group.

A

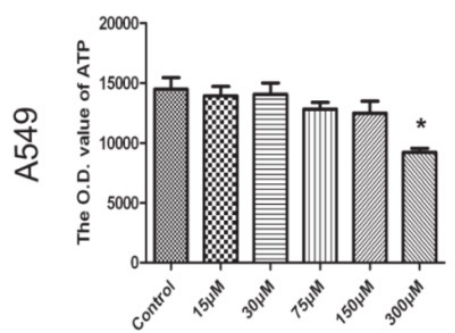

B
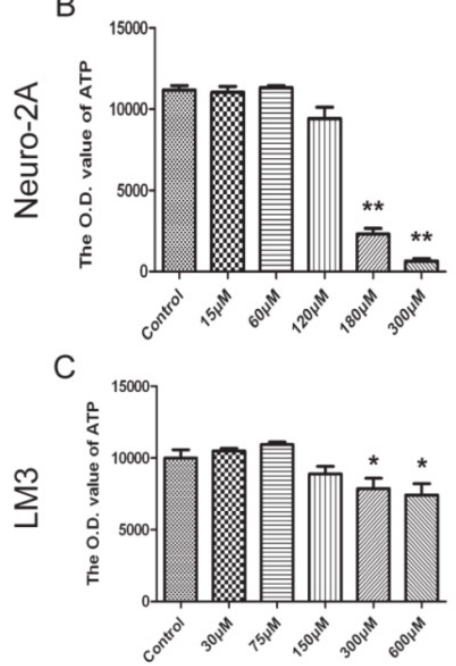

$12 \mathrm{~h}$
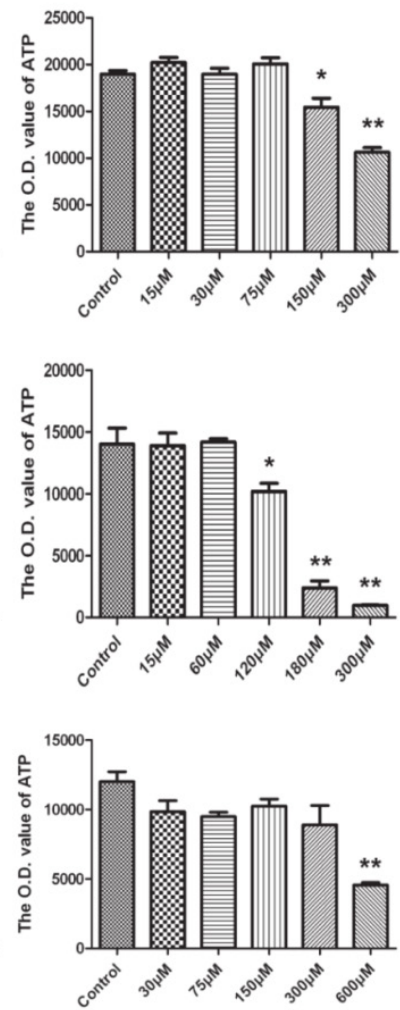

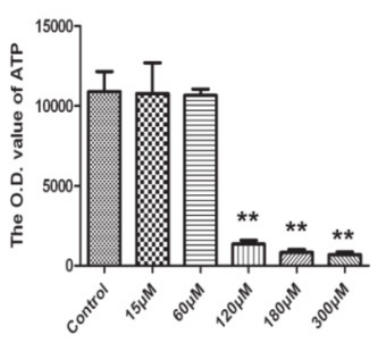

$24 \mathrm{~h}$
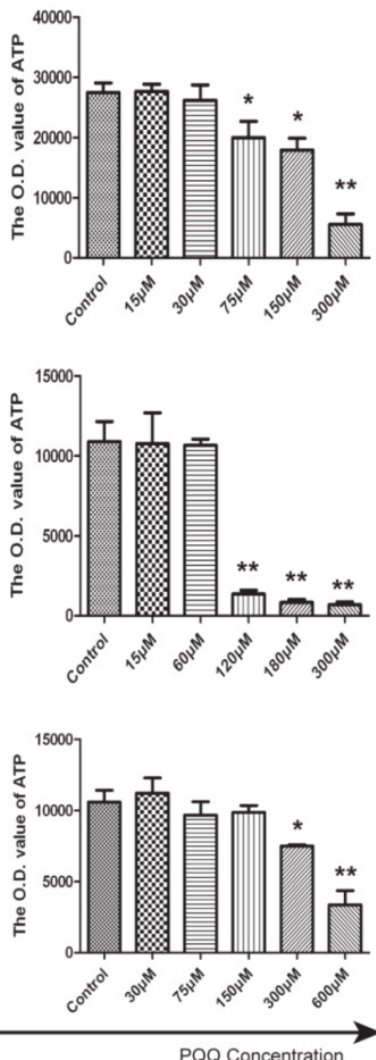


\section{Increased activity of intracellular caspase-3 after PQQ treatment}

The expression levels of activated caspase-3 after 24h PQQ treatment increased in dose-dependent manner in the 3 tumor cell lines (Figure 6). Compared to the negative control, the fluorescent intensity of activated caspase- 3 in A549 cells showed a trend of enhancing $(15.50 \pm 0.89$ vs $15.50 \pm 0.89$ at $15 \mu \mathrm{M}, \mathrm{p}>$ $0.05 ; 18.43 \pm 1.19$ vs $15.50 \pm 0.89$ at $30 \mu \mathrm{M}, \mathrm{p}<0.05$; $22.90 \pm 1.54$ vs $15.50 \pm 0.89$ at $75 \mu \mathrm{M}, \mathrm{p}<0.01 ; 42.83 \pm$ 3.15 vs $15.50 \pm 0.89$ at $300 \mu \mathrm{M}, \mathrm{p}<0.01$ ) (Figures 6A and $6 \mathrm{~B})$. A similar trend was observed in Neuro-2A cells (Figures 6C and 6D). The fluorescent intensity of activated caspase- 3 cells was significant increased in all PQQ treatment groups compared to the control $(5.23 \pm 0.08$ vs $5.02 \pm 0.05$ at $15 \mu \mathrm{M}, \mathrm{p}<0.05 ; 8.54 \pm 0.59$ vs $5.02 \pm 0.05$ at $60 \mu \mathrm{M}, \mathrm{p}<0.01 ; 27.47 \pm 1.12$ vs $5.02 \pm$ 0.05 at $300 \mu \mathrm{M}, \mathrm{p}<0.01)$. PQQ treatment increased the expression levels of caspase-3 in HCC-LM3 cells too. As shown in Figures 6E and 6F, a gradually rise of the fluorescent intensity of caspase-3 was seen in a dose-dependent manner $(9.80 \pm 1.66$ vs $8.86 \pm 0.07$ at $30 \mu \mathrm{M}, \mathrm{p}>0.05 ; 12.30 \pm 0.53$ vs $8.86 \pm 0.07$ at $75 \mu \mathrm{M}, \mathrm{p}$

A
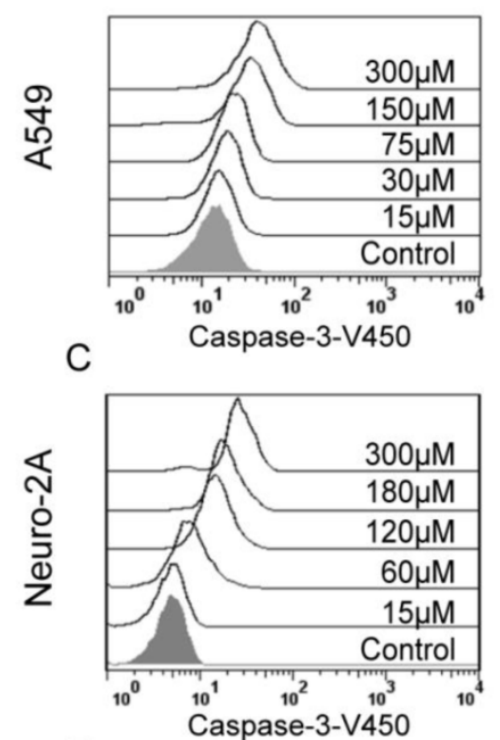

E

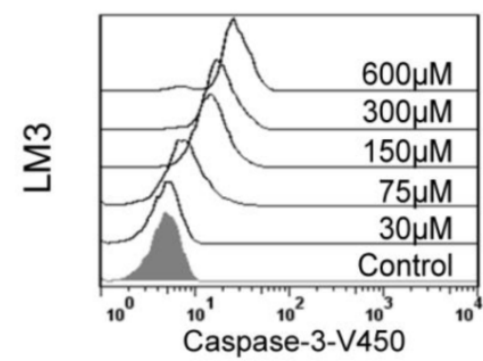

$<0.01 ; 17.30 \pm 0.70$ vs $8.86 \pm 0.07$ at $600 \mu \mathrm{M}, \mathrm{p}<0.01)$.

\section{Effects of PQQ on cell cycle regulation in A549 and Neuro-2A cells}

The cell cycle status of the A549 and Neuro-2A cancer cells were measured after PQQ treatment of $15-360 \mu \mathrm{M}$ at $24 \mathrm{~h}$ respectively. Cell cycle distribution analysis revealed an increasing rate of both tumor cells in sub-G0/G1 phase, with reduced counts of cells in $S$ and $\mathrm{G}_{2} \mathrm{M}$ phases (Figure 7). After PQQ treatment for $24 \mathrm{~h}$, the sub-G0/G1 population significantly increased from $0.47 \pm 0.07 \%$ (control) to $17.55 \pm 1.73 \%$ $(150 \mu \mathrm{M}, p<0.05$, Figures 7A and 7B) in A549 cells; and from $2.89 \pm 0.66 \%$ (control) to $42.93 \pm 0.94 \%$ (360 $\mu \mathrm{M}, p<0.05$, Figures 7C and 7D) in Neuro-2A cells. The percentage of A549 cells in G0/G1 phase increased from $47.81 \pm 1.23 \%$ (control) to $59.64 \pm 0.68 \%$ $(150 \mu \mathrm{M}, p<0.05)$. Correspondingly, the percentage of cells in $\mathrm{S}$ and $\mathrm{G}_{2} \mathrm{M}$ phase decreased from $36.66 \pm 1.13 \%$ (control) to $15.63 \pm 1.07 \%(150 \mu \mathrm{M}, p<0.05)$ in A549 cells; and from $14.90 \pm 0.57 \%$ (control) to $7.19 \pm 0.34 \%$ $(150 \mu \mathrm{M}, p<0.05)$ in $\mathrm{A} 549 \mathrm{G}_{2} \mathrm{M}$ phase cells. However, no obvious rise in the percentage of G0/G1, S and $\mathrm{G}_{2} \mathrm{M}$ phase was found in Neuro-2A cells.
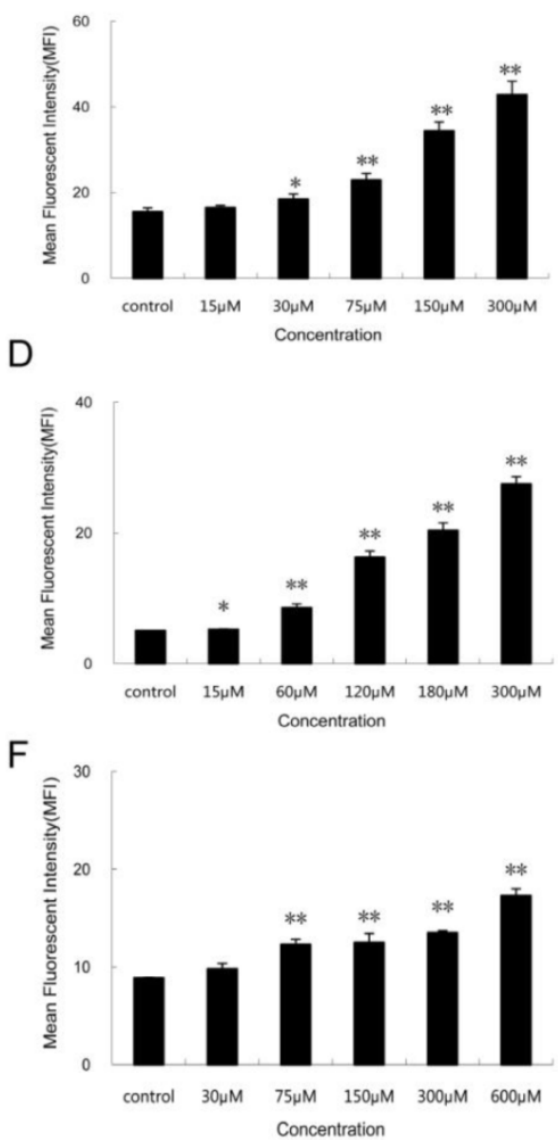

Figure 6. Activity of caspase-3 in the 3 cancer cell lines treated with PQQ. Effects of PQQ on caspase-3 expression in the 3 cancer cells for $24 \mathrm{~h}$. Levels of the activated caspase-3-V450 were quantitatively measured by flow cytometer and presented as mean fluorescent intensity (MFI). The overlay histograms (panels $\mathrm{A}, \mathrm{C}$ and $\mathrm{E}$ ) and histograms (panels B, D and F) respectively indicated caspase-3 expression at protein level after treatment with various concentrations of PQQ for $24 \mathrm{~h}$ in the 3 cancer cells. The data are represented as means \pm SEM from three-independent experiments. $* p<0.05$ as compared with control group; $* * p<0.01$ as compared with control group. 

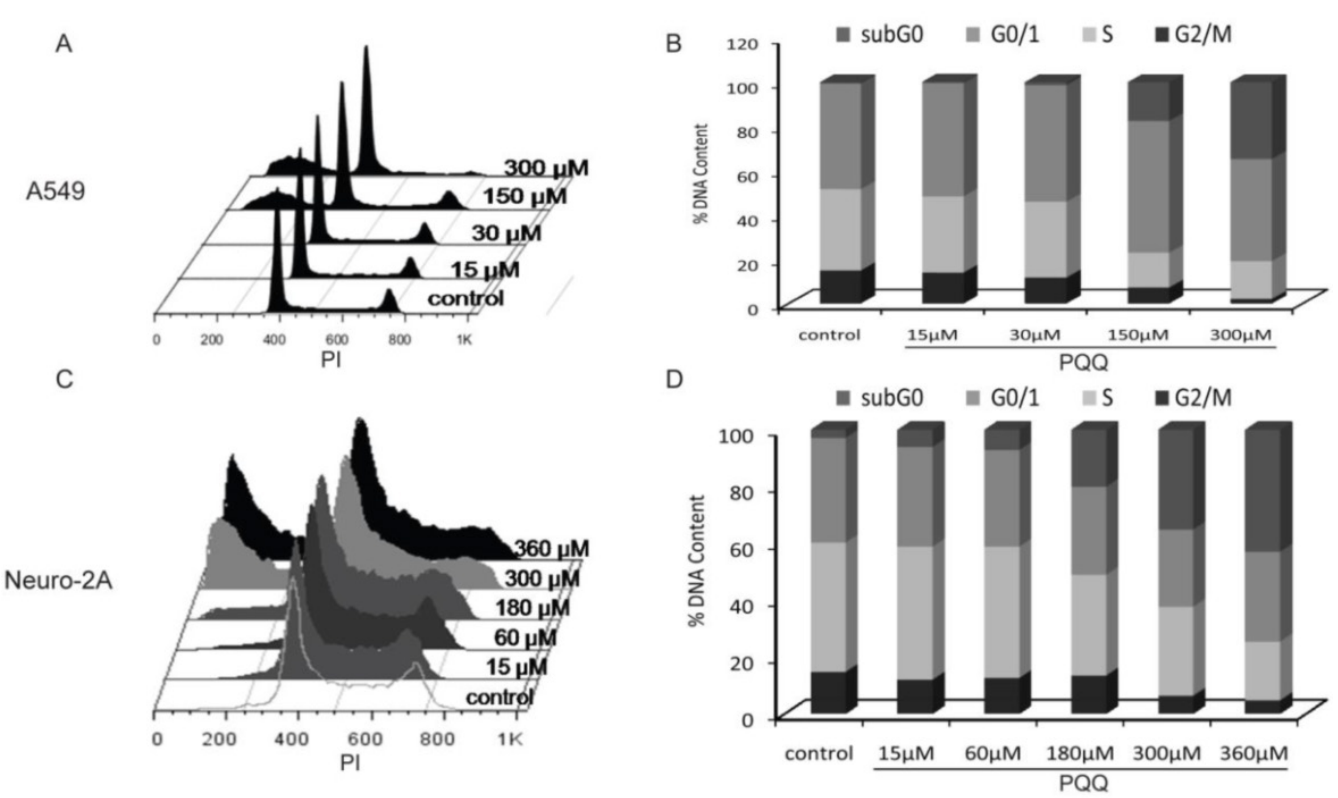

Figure 7. Effects of PQQ on cell cycle regulation in A549 and Neuro-2A cells. Flow cytometry analysis of cell cycle distribution of A549 and Neuro-2A cells. The 2 cell lines were treated with $\mathrm{PQQ}$ at the indicated concentrations for $24 \mathrm{~h}$. Effects of $\mathrm{PQQ}$ on cell cycle were investigated using PI (Propidium lodide) staining subjected to flow cytometry (panels $A$ and $C$ ). The peaks from left to right represent sub-G0/GI phase, G0/GI phase, $S$ phase and $\mathrm{G}_{2} \mathrm{M}$ phase respectively. Represent cells in different phases from three independent experiments (panels B and D).

\section{Decreased mitochondrial membrane potential after PQQ treatment}

A549 and Neuro-2A cancer cells stained with JC-1 emitted mitochondrial red fluorescence with a little green fluorescence, indicative of normal polarization state. JC- 1 is a cationic dye that manifests mitochondrial polarization by shifting its fluorescence emission from green $(\sim 525 \mathrm{~nm})$ to red $(\sim 590 \mathrm{~nm})$. When cell apoptosis occurs, the mitochondrial membrane potential depolarization is produced. JC-1 probe was released from mitochondria and red fluorescence intensity decreased, while the monomer of green fluorescence mainly existed in the cytoplasm. The JC-1 aggregates were dispersed to the monomeric form (green fluorescence) in both the cancer cells subjected to PQQ for $24 \mathrm{~h}$ in a concentration-dependent manner. As shown in figures $8 \mathrm{~A}$ and 8C, red fluorescent percentages of JC- 1 of A549 cells significantly decreased from $79.5 \%$ (15 $\mu \mathrm{M}$ PQQ) to $18.7 \%(300 \mu \mathrm{M} P Q Q)$, compared with the negative control group $(92.7 \%), p<0.01$ respectively; the ratio of JC-1 red/green MFI was indicated to a significant reduction starting from the dose of $15 \mu \mathrm{M}$ PQQ $(0.47 \pm$ $0.01)$, compared to the negative control $(0.70 \pm 0.03), p$ $<0.01$. Similarly, in Neuro-2A cells, the percentage of JC-1 aggregates significantly decreased from $94.2 \%$ of the control group to $91.2 \%$ of $15 \mu \mathrm{M}$ PQQ and $10.3 \%$ of $360 \mu \mathrm{M}$ PQQ group. The ratios of JC-1 red/green MFI were decreased with the increasing of PQQ concentrations from $0.80 \pm 0.02$ (negative control) to $0.66 \pm$ $0.05(15 \mu \mathrm{M}, p<0.05)$, and $0.11 \pm 0.02(360 \mu \mathrm{M}, p<$ 0.01 ) (Figures $8 \mathrm{~B}$ and $8 \mathrm{D}$ ).

\section{Decreased expression of Bcl-2 by PQQ treatment}

In order to delineate the possible mechanisms by which PQQ induced apoptosis we quantitatively examined the cytoplasmic levels of the Bcl-2 protein by flow cytometer. As shown in Figure 9, compared to the controls, the Bcl-2 levels in both tumor cells were decreased after treatment with different doses of PQQ for $24 \mathrm{~h}$. In A549 cells, except for the $15 \mu \mathrm{M}$ PQQ group that the MFI of Bcl-2 protein was higher than that of the control group $(19.23 \pm 0.40$ vs $17.77 \pm 0.72, p<0.05)$, with the PQQ concentrations increased from $30 \mu \mathrm{M}$ to $300 \mu \mathrm{M}$, the mean fluorescent intensity (MFI) of Bcl-2 protein decreased (11.57 \pm 0.86 vs $17.77 \pm 0.72$ at 30 $\mu \mathrm{M}, p<0.01 ; 10.01 \pm 0.45$ vs $17.77 \pm 0.72$ at $300 \mu \mathrm{M}, p<$ 0.01 ) (Figures 9A and 9B). Similar pattern was found in neuro-2A cells, the expression levels of $\mathrm{Bcl}-2$ significantly decreased with the increasing of PQQ concentrations, beginning at $15 \mu \mathrm{M}$ (Figures 9C and 9D).

\section{Effects of PQQ on ERK2, MEK2, pERKI/2 and p38 MAPK pathway}

As shown in Figure 10, with the increasing of PQQ concentrations, increased expression levels of ERK2 (13.00 \pm 1.45 vs $9.16 \pm 0.57$ at $30 \mu \mathrm{M}, p<0.01$; $35.30 \pm 1.86$ vs $9.16 \pm 0.57$ at $300 \mu \mathrm{M}, p<0.01)$, MEK2 (36.70 \pm 1.08 vs $18.30 \pm 0.55$ at $15 \mu \mathrm{M}, p<0.01 ; 47.00 \pm$ 1.74 vs $18.30 \pm 0.55$ at $300 \mu \mathrm{M}, p<0.01)$, pERK1/2 (28.57 \pm 0.87 vs $16.23 \pm 0.35$ at $15 \mu \mathrm{M}, p<0.01 ; 39.11 \pm$ 0.56 vs $16.23 \pm 0.35$ at $300 \mu \mathrm{M}, p<0.01$ ) and p38 MAPK $(16.53 \pm 1.07$ vs $9.60 \pm 0.24$ at $15 \mu \mathrm{M}, p<0.01 ; 23.93 \pm$ 
0.59 vs $9.60 \pm 0.24$ at $300 \mu \mathrm{M}, p<0.01$ ) in A549 cells were detected after $24 \mathrm{~h}$ PQQ treatment, compared with the control group. The MFIs of ERK2 and MEK2 A

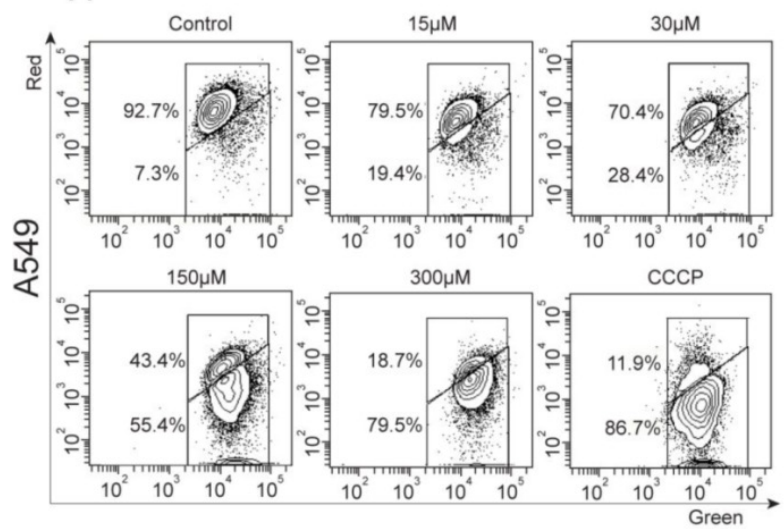

B
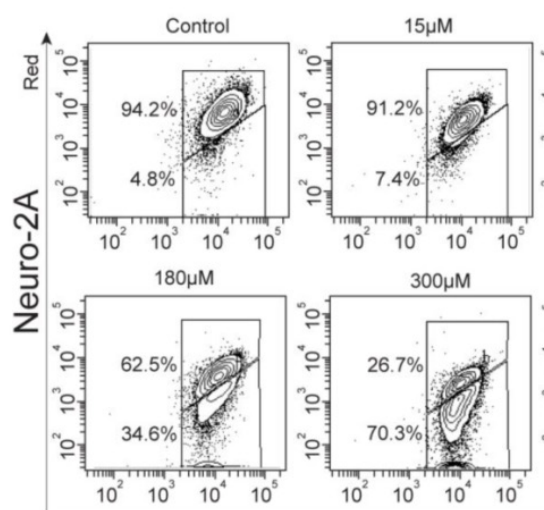

$60 \mu \mathrm{M}$
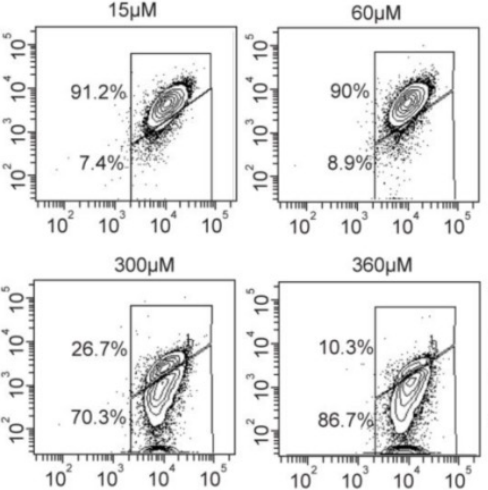

in neuro-2A cells were significantly decreased and the MFI of pERK1/2 were significantly increased, when compared to the control group.

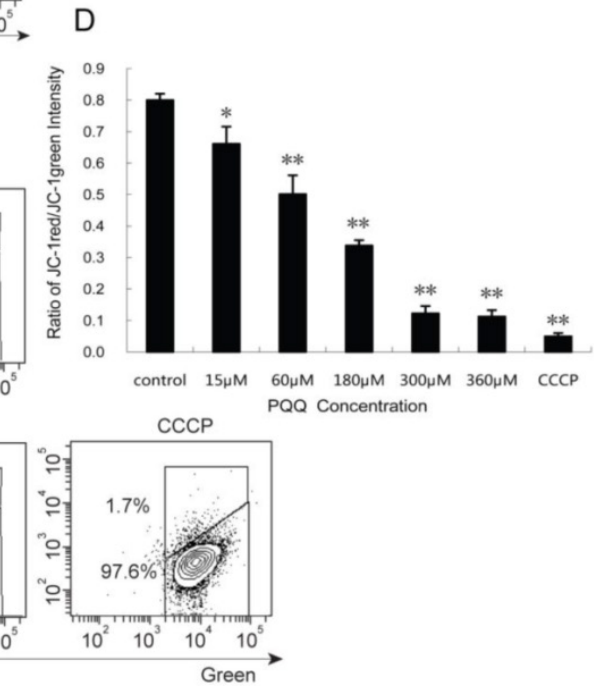

C

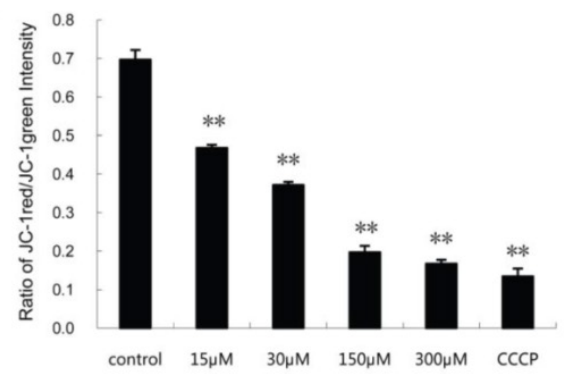

PQQ Concentration

Figure 8. Decreased mitochondrial membrane potential after PQQ treatment. PQQ decreased mitochondrial membrane potential in A549 and Neuro-2A cells. Density diagram of flow cytometry analysis showed the distribution of JC-I aggregates (red) and JC-I monomer (green) in the mitochondrial membrane with A549 and Neuro-2A cell lines, respectively (panels A and B). A549 and Neuro-2A cells without PQQ treatment served as controls and CCCP used as positive-control. Both the cell lines were treated with different concentrations of PQQ (from I5 $\mu \mathrm{M}$ to $360 \mu \mathrm{M}$ ) for $24 \mathrm{~h}$ and then stained with IC-I before flow cytometry analysis. Quantitative analysis of the shift of mitochondrial red fluorescence to green fluorescence among groups was calculated as red/green fluorescence intensity value (panels $C$ and $D$ ). All values are showed as means \pm SEM from three-independent experiments. ${ }^{*} p<0.05$ as compared with control group; $*^{*} p<0.01$ as compared with control group.

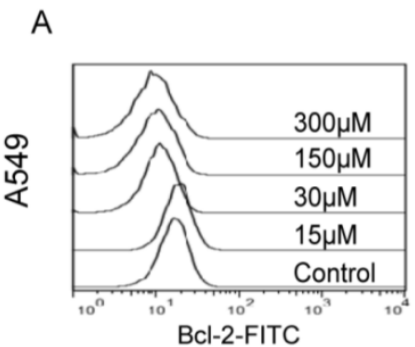

C

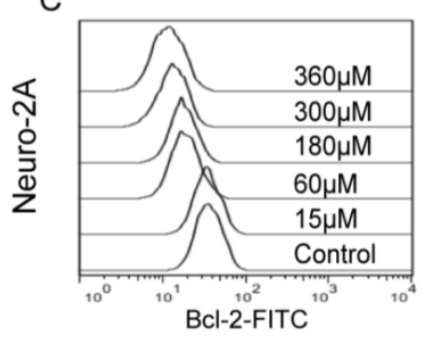

B

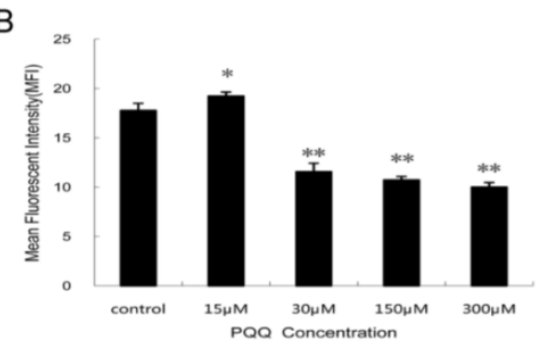

D

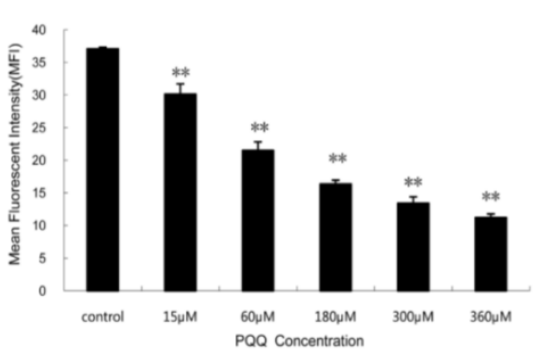

Figure 9. Decreased expression of Bcl-2 by PQQ treatment. Effects of PQQ on Bcl-2 expression in A549 and Neuro-2A cells for $24 \mathrm{~h}$. Levels of the cytoplasmic Bcl-2 protein were quantitatively measured by flow cytometer and presented as mean fluorescent intensity (MFI). The overlay histograms (panels $\mathrm{A}$ and $\mathrm{C}$ ) respectively indicated $\mathrm{Bcl}-2$ expression at protein level of the 2 cell lines after treatment with various concentrations of PQQ for $24 \mathrm{~h}$. Bar diagram (panels B and D) represent MFI values from three-independent experiments as means \pm SEM. $* p<0.05$ as compared with control group; $* * p<0.01$ as compared with control group. 

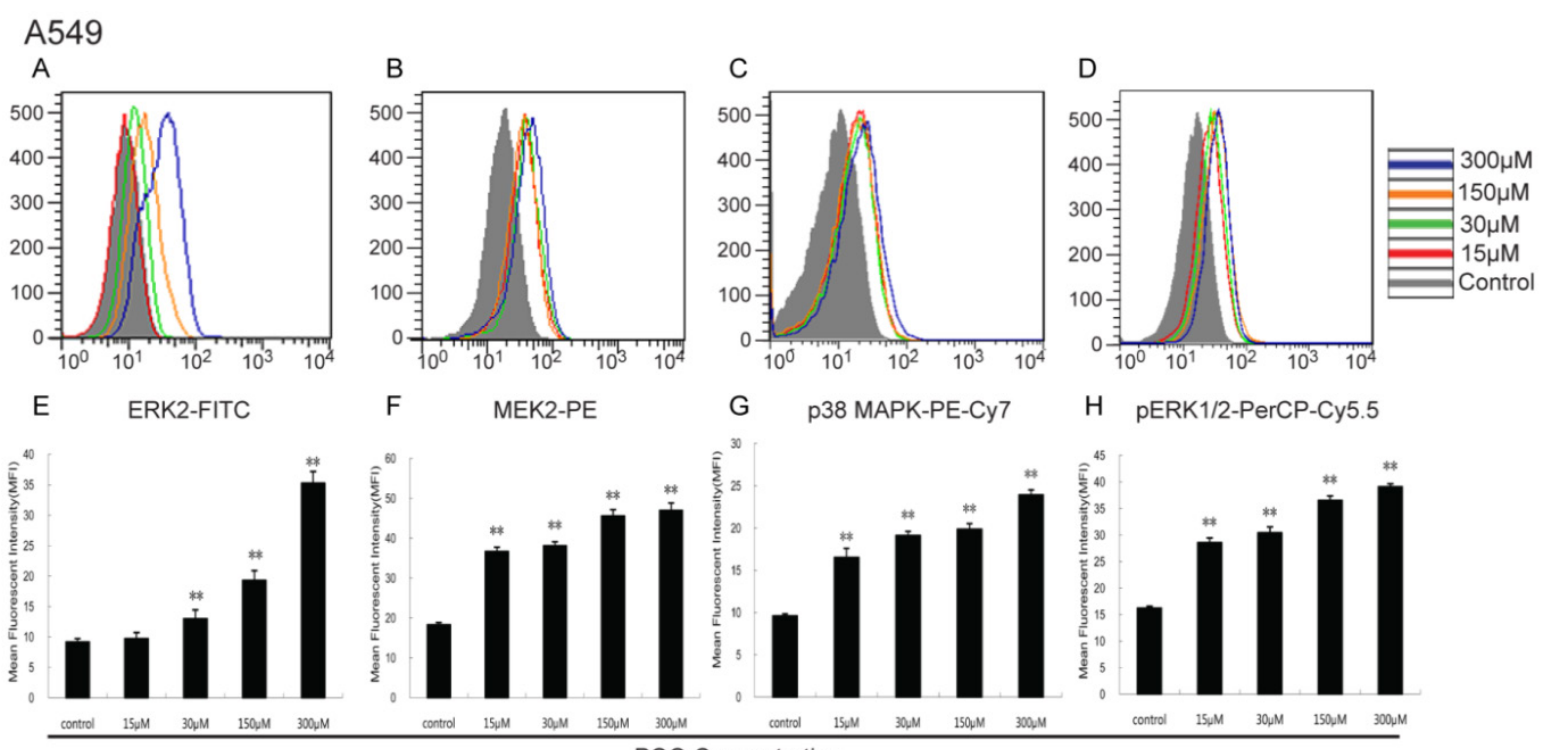

Neuro-2A

I

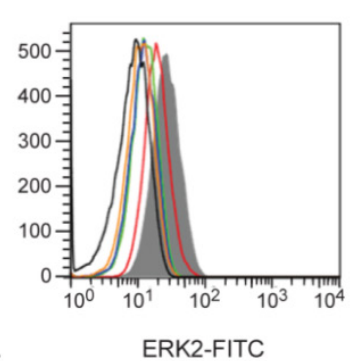

$\mathrm{J}$

PQQ Concentration
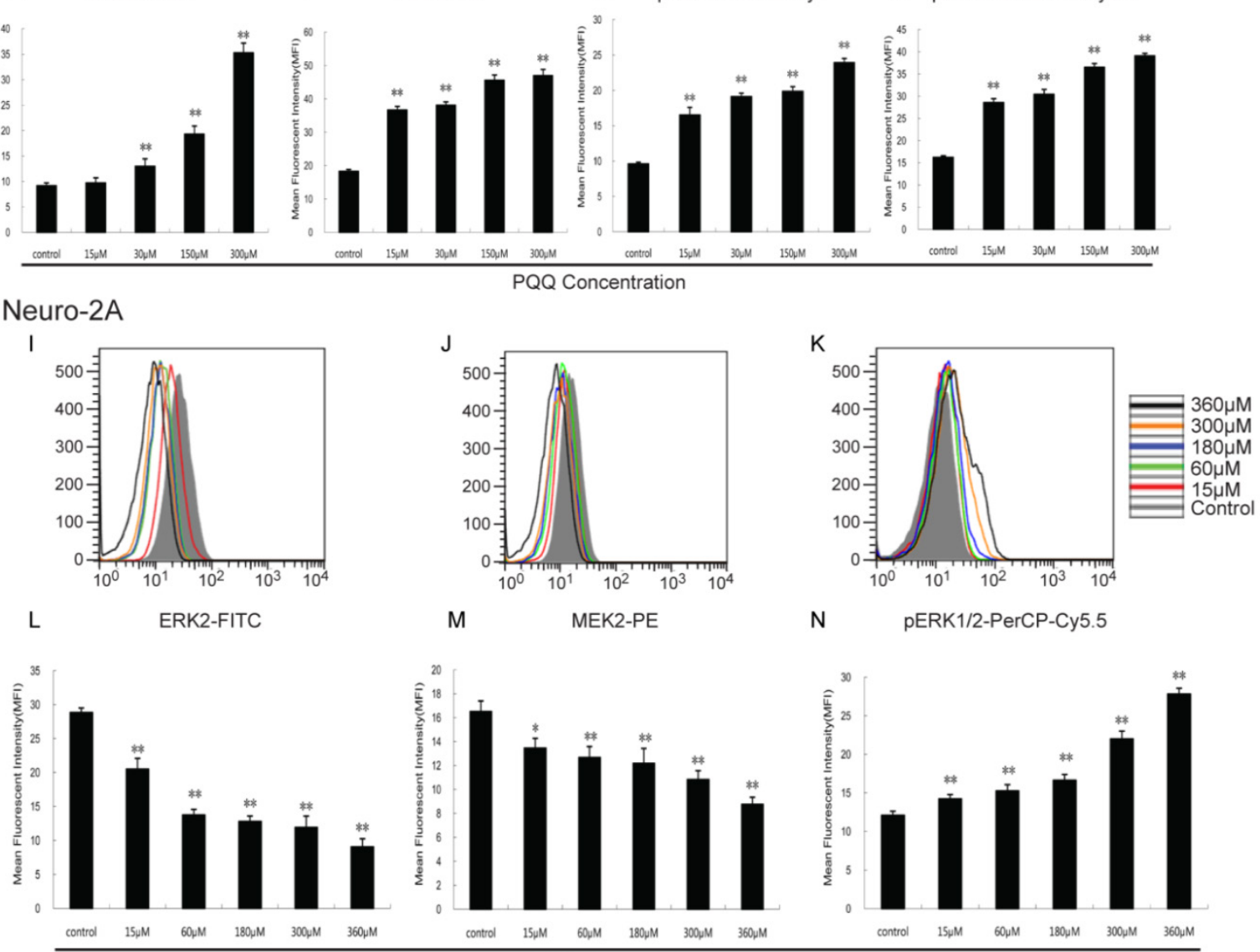

PQQ Concentration

Figure 10. Effects of PQQ on ERK2, MEK2, pERKI/2 and p38 MAPK pathway. Effects of PQQ on biomarkers of apoptotic signal pathway in A549 and Neuro-2A cells at 24h. Phosphorylated ERKI/2 and p38 MAPK, ERK2 and MEK2 levels were represented as mean fluorescent intensity (MFI) measured by flow cytometer (panels A to D, and panels I to K). The overlay graphs respectively indicated the levels of proteins related to the signal transduction pathways in the 2 cell lines after treatment with various concentrations of $\mathrm{PQQ}$ for $24 \mathrm{~h}$ (panels $\mathrm{E}$ to $\mathrm{H}$, and panels $\mathrm{L}$ to $\mathrm{N}$ ). The bar diagram represented the corresponding mean fluorescent intensity of protein level. All values are showed as means \pm SEM from three-independent experiments. ${ }^{*} p<0.05$ as compared with control group; ${ }^{*} p<0.01$ as compared with control group.

\section{Discussion}

PQQ, as an antioxidant nutrient, has the effects of radioprotection and neuroprotection. Previous study focused on the scavenging of the production of intracellular ROS [13], which was due to comparatively higher reactive electron density and the structure of indole and pyrrole derivatives. Thus PQQ exhibits strong antioxidant feature [5]. Recently, study showed that higher concentrations of $\mathrm{PQQ}$ (50-100 $\mu \mathrm{M})$ could result in 2-5 fold increase in apoptosis-inducing of U937 human promonocytic lymphoma cells through the depletion of cellular gluta- thione and the increasing of intracellular ROS [9]. Other studies also demonstrated that PQQ could regulate cell function of different cells and induce cell apoptosis, directly or indirectly $[5,10,11]$. However, there is no study that has investigated the effect of PQQ on directly inducing solid tumor cell apoptosis and the associated mechanisms.

In this study, the apoptosis of three tumor cell lines (Neuro-2A, A549 and HCC-LM3) induced by PQQ were measured and the potential mechanisms were investigated. The result showed that the proliferations of three cell lines were suppressed by PQQ in a dose- and time-dependent manner. PQQ exhibited 
potent anti-cancer activity while imposed comparably minimal cytotoxicity to 2 normal cell lines (HRPTEpiC and HUVEC), a finding concordant with previous reports that PQQ would stimulate the normal cell lines (A431 and NIH3T3) proliferation [14, 15]. Typical apoptotic cellular morphological changes such as poor growth, membrane blebbing, cellular shrinkage and chromatin condensation were observed with real-time cell monitoring system. Moreover, flow cytometry and Annexin V-FITC/PI staining showed that the percentages of apoptosis caused by PQQ in A549 and Neuro-2A cells were increased in a dose-dependent manner. PQQ-induced apoptosis of the 3 tumor cell lines were all alleviated by the treatment of Z-VAD-FMK, a pan-caspase inhibitor (Figure $3)$, which confirmed the participation of caspase in PQQ-induced apoptosis. The fact that Z-VAD-FMK could not completely block PQQ-induced apoptosis, suggesting other pathways involvement in the PQQ-induced cell apoptotic process. However, the caspase-dependent pathway might play a leading role, considering the significantly 2-fold decrease of apoptosis in A549 cells after Z-VAD-FMK treatment.

PQQ triggered apoptotic process at lower concentrations $(30-75 \mu \mathrm{M})$, and the apoptotic effects became significant at higher concentrations (120-300 $\mu \mathrm{M})$. This finding is concordant with a previous study that PQQ induced programmed Jurkat cell death by increasing the caspase-3 activity [5]. The proliferation inhibition and apoptosis-inducing effects of PQQ were less remarkable in HCC-LM3 cells at lower concentrations than that in A549 and Neuro-2A cells. It suggested that different tumor cells have different sensitivities to PQQ. Nonetheless, the results indicated that the apoptosis of HCC-LM3 cell induced by PQQ was also probably via the caspase-dependent pathway. Taken together, the growth inhibitory effects of PQQ on solid tumor cells of A549, Neuro-2A and HCC-LM3 were demonstrated to be largely resulted from apoptosis.

The current study measured intracellular ROS production, ATP release, mitochondrial membrane potential, cell cycle distribution and related protein signaling pathways to explore the anti-tumor and apoptosis-inducing mechanisms of PQQ. ROS plays a vital role in apoptosis induction under both physiological and pathological conditions. The major source of intracellular ROS is mitochondria [16]. Numerous evidences suggest that impaired mitochondria could stimulate ROS generation, continuous accumulation of ROS triggers apoptosis via the intrinsic pathway by opening of mitochondrial permeability transition pore (PTP) and collapsing of mitochondrial membrane potential, ultimately caused caspase- 3 activation and cell death [17, 18]. Our data indicated that PQQ treatment resulted in an enhanced generation of ROS in time- and dose-dependent manner in all 3 tumor cells. In Neuro-2A cells the accumulation of ROS preceded the other 2 cell lines. It might suggest that Neuro-2A cells are more sensitive to PQQ treatment on ROS production. Collectively, these data suggested that the PQQ-induced apoptosis is associated with ROS generation, which is in agreement with previous report [9].

Cellular ATP content is associated with the number of metabolically viable cells. Our data showed that PQQ treatment decreased the cellular content of ATP in a time- and dose-dependent manner in all the 3 tumor cells. Decreased ATP contents of HCC-LM3 cells were only apparent when exposed to higher concentrations of $P Q Q$, suggesting that the liver cancer cells might have a higher tolerance to PQQ. Our results also indicated that PQQ could dissipate mitochondrial membrane potential of A549 and Neuro-2A cells in a concentration-dependent manner, which might be related with decreased cellular ATP content and enhanced generation of ROS after PQQ treatment. Previous study [19] reported that in apoptotic cells, the loss of mitochondrial ATP synthesis and the increase of inter-membrane creatine phosphate concentrations might be consequences of the loss of mitochondrial membrane potential caused by the translocation of proapoptotic $\mathrm{BH} 3$ proteins to the mitochondria. The mitochondria play a crucial role in cell intrinsic apoptosis pathway. The mitochondrial membrane permeability transition is a critical step in the induction of intrinsic apoptosis and often represents the earliest apoptotic signal [20]. During apoptosis, mitochondria suffer specific damages that result in loss of function, and release of cytochrome $c$ that can potentially halt the electron transfer, leading to failure in maintaining the mitochondrial membrane potential and ATP synthesis [21].

The sub-G0/G1 phase, appearing left to the G0/G1 peak in DNA distribution, represents the cell population undergoing apoptosis. The current results showed that with the increasing concentration of PQQ, significant apoptotic peak appeared in A549 and Neuro-2A cells. The cell cycle data suggested that the number of A549 and Neuro-2A cells entering the cell cycle decreased with the increasing of PQQ concentration (Figure 7A-7D). This pointed to G0/G1 arrest as one of the mechanisms for PQQ inhibition of A549 cell growth. Studies reported that Usnic Acid and Tanshinone treated A549 cells also resulted in G0/G1 arrest, which possibly could be associated with decreased expression of cyclin-dependent kinase (CDK)4, CDK6, and Cyclin D1, and inhibition of Cyclin A and Cyclin B [22, 23]. In Neuro-2A cells, no significant cell cycle arrest was observed. However, 
combined with the results of ROS and ATP experiments, of which the production of ROS reached the peak at $12 \mathrm{~h}$ and fall at $24 \mathrm{~h}$, and the ATP production significantly declined from $12 \mathrm{~h}$ to $24 \mathrm{~h}$, implying that the occurrence of ROS accumulation and ATP declining might happen prior to the cell cycle changes. This supports a major role of the ROS-mediated mitochondrial pathway in the PQQ-induced Neuro-2A cell apoptosis, concordant with previous studies [24, 25].

Bcl-2 is an anti-apoptotic protein known as a mitochondrial membrane protein which can block programmed cell death and tumorigenesis upon activation [26]. The Bcl-2 protein family controls the integrity of the outer-mitochondrial membrane. During apoptosis, the change of anti- and pro-apoptotic proteins of Bcl-2 family causes the mitochondrial membrane potential across the membrane to collapse, leading to the release of cytochrome $c$ into the cytoplasm, the formation of the apoptosome and an increase in effector caspase activities, thereby resulting in apoptosis [27-29]. Caspase activation is generally considered a key hallmark of apoptosis in these pathways [30]. Our results demonstrated that the expression levels of activated caspase- 3 were increased in a dose-dependent manner in 3 cell lines, which implied the participation of caspase- 3 in the PQQ-induced apoptosis. Given the fact that caspases play a central role in the apoptotic cascade, these results strongly supported the hypothesis that PQQ treatment causes the collapses of the mitochondrial membrane potential and the reductions of Bcl-2 protein, and initiates the corresponding elevation of activated caspase-3. This finding was backup by recent studies reporting that grape seed proanthocyanidins induces apoptosis of A549 by loss of mitochondrial membrane potential, G1 phase arresting, down-regulation of the anti-apoptotic proteins Bcl-2 and activation of caspases 9 and 3 [31]. The activation of A549 cellular apoptosis signal is conducted via Bcl-2 suppression and p53 and Bax activation [32]. The butein-induced Neuro-2A cells apoptosis is characterized by increased intracellular reactive oxygen species (ROS) levels and reduced Bcl-2/Bax ratio [25]. Taken together, we propose that the apoptosis-inducing effect of PQQ on A549 and Neuro-2A cells is partly through the loss of mitochondrial membrane potential and reduction of Bcl-2 protein.

Aberrant activation of the signaling pathway was frequently observed in human tumor cells, however, little is known about the effect of PQQ on tumor cell signaling pathway. There are 4 mitogen-activated protein kinase (MAPK) families categorized by sequence homology and functions: ERK1/2 (extracellular signal-regulated kinase), p38, JNK (c-Jun
N-terminal kinase), and ERK5 [33]. Activation of p38MAPK is predominantly implicated in inducing cancer cell apoptosis and displaying pro-apoptosis by several chemotherapeutic drugs in experimental settings [34-36]. PQQ seemed to modulate cell apoptosis and mitochondrial assembly signaling pathways [37, 38]. In the current study, the expressions of p38MAPK, pERK1/2, ERK2 and MEK2 in A549 cells were markedly up-regulated by PQQ at $15-300 \mu \mathrm{M}$. The results were also supported by the study reporting that activation of JNK and p38MAPK caused phosphorylation and translocation of Bax into mitochondria to cause apoptosis via intrinsic pathway [39]. ERK is well known as one of the MAPKs and for its prominent role in controlling proliferation, differentiation and cell survival [40]. The ERK1/2 are activated by external and internal stimuli in numerous cell types and played a central role in many signal transduction pathways, which can directly phosphorylate many target proteins including transcription factors (c-Jun, c-Myc, P53), leading to the induction of many cell cycle proteins (p21, Cyclin D1, cdk1) and then the activation of transcription factor and apoptotic factors (caspase 9, bad, Bim), and finally cause cell death [41, 42].

Our data demonstrated that the expression levels of intracellular ERK2 were notably increased 3-fold compared to that of the control group in A549 cells, which would suggest that ERK2, probably activated by PQQ treatment, induces p53 up-expression and Bcl-2 suppression [31, 32], Cyclin D1 and CDK4,6 inhibition [22], while blocking cell cycle progression, eventually promotes the caspase cascade reaction, resulting in cell apoptosis. This inference is in concordance with a previous report [43]. However, using probes to quantify the levels of these MAPKs in Neuro-2A cells exhibited that PQQ treatment caused significant decrease in levels of ERK2 and MEK2, but increase of $\mathrm{pERK} 1 / 2$ levels, and have no effect on p38MAPK levels (data not shown), suggesting that this effect may be cell type specific. Previous study reported that the anti-epileptic drug valproic acid increased the degree of ERK1/2 phosphorylation in Neuro-2A and BT4Cn cells as well [44]. These results are in agreement with other recent works $[45,46]$. These observations permit us to propose that PQQ concentration greater than $15-30 \mu \mathrm{M}$ may exert its apoptosis-inducing effect on A549 and Neuro-2A cells via the aforementioned mechanisms. However, other molecular mechanism for the pro-apoptosis effects of PQQ remains to be determined.

The authors acknowledge that these findings need to be further investigated in in vivo settings, and in the current study no positive controls were included which might jeopardize the power of the re- 
sults. It might be argued that currently there is no compound with similar molecular structures in clinical application that could be used as a reference. Thus, the current study focused primarily on the anti-tumor effects of PQQ and highlighted the associated potential mechanisms. In summary, despite the limitations, this work does for the first time report the effects of PQQ on solid tumor cells of A549, Neuro-2A and HCC-LM3 in vitro, that PQQ could outstandingly suppress the A549 and Neuro-2A cell proliferation through the mitochondrial-dependent apoptosis pathway while have comparably minimal toxicity towards normal cells. The underlying mechanisms might include, but not limited to, cell cycle arrest at G0/G1 phase, accumulation of intracellular ROS, decline in ATP levels, disruption of mitochondrial membrane potential in conjunction with down-regulation of Bcl-2 protein expression and enhancement of the activated caspase- 3 expression, and the enrichment of signal pathway proteins of p38MAPK, pERK1/2, ERK2 and MEK2 in A549 cells; reduction of ERK2 and MEK2 in Neuro-2A cells. The significance of our findings is the possibility of developing new venues to target cancers. However, as the anti-tumor activity of PQQ is cell type specific, why some tumor cells are sensitive to it and others are not needs to be further investigated. Future studies on the mechanistics and the potential role of PQQ in cancer prevention and treatment are warranted.

\section{Acknowledgments} reagent.

We thank Mr Qunye Tang for providing the ATP

This study is supported by National Science Foundation of China (Grant No. 30972737 and 81170473), Young Scholars of Fudan University (Grant No. 431), and Pujiang talent research grant (Grant No. 10PJ1403600) from the Shanghai Committee of Science and Technology.

\section{Competing Interests}

The authors have declared that no competing interest exists.

\section{References}

1. Salisbury SA, Forrest HS, Cruse WB, Kennard O. A novel coenzyme from bacterial primary alcohol dehydrogenases. Nature. 1979; 280: 843-4.

2. Kasahara T, Kato T. Nutritional biochemistry: A new redox-cofactor vitamin for mammals. Nature. 2003; 422: 832. doi:10.1038/422832a.

3. Kumazawa T, Sato K, Seno H, Ishii A, Suzuki O. Levels of pyrroloquinoline quinone in various foods. The Biochemical journal. 1995; 307 ( Pt 2): 331-3.

4. Noji N, Nakamura T, Kitahata N, Taguchi K, Kudo T, Yoshida S, et al. Simple and sensitive method for pyrroloquinoline quinone (PQQ) analysis in various foods using liquid chromatography/electrospray-ionization tandem mass spectrometry. Journal of agricultural and food chemistry. 2007; 55: 7258-63. doi:10.1021/jf070483r.

5. He K, Nukada H, Urakami T, Murphy MP. Antioxidant and pro-oxidant properties of pyrroloquinoline quinone (PQQ): implications for its function in biological systems. Biochemical pharmacology. 2003; 65: 67-74.
6. Tao R, Karliner JS, Simonis U, Zheng J, Zhang J, Honbo N, et al. Pyrroloquinoline quinone preserves mitochondrial function and prevents oxidative injury in adult rat cardiac myocytes. Biochemical and biophysical research communications. 2007; 363: 257-62. doi:10.1016/j.bbrc.2007.08.041.

7. Hara H, Hiramatsu H, Adachi T. Pyrroloquinoline quinone is a potent neuroprotective nutrient against 6-hydroxydopamine-induced neurotoxicity. Neurochemical research. 2007; 32: 489-95. doi:10.1007/s11064-006-9257-x.

8. Xiong XH, Zhao Y, Ge X, Yuan SJ, Wang JH, Zhi JJ, et al. Production and radioprotective effects of pyrroloquinoline quinone. International journal of molecular sciences. 2011; 12: 8913-23. doi:10.3390/ijms12128913.

9. Shankar BS, Pandey R, Amin P, Misra HS, Sainis KB. Role of glutathione in augmenting the anticancer activity of pyrroloquinoline quinone (PQQ). Redox report : communications in free radical research. 2010; 15: 146-54. doi:10.1179/174329210X12650506623762.

10. Tchaparian E, Marshal L, Cutler G, Bauerly K, Chowanadisai W, Satre M, et al. Identification of transcriptional networks responding to pyrroloquinoline quinone dietary supplementation and their influence on thioredoxin expression, and the JAK/STAT and MAPK pathways. The Biochemical journal. 2010; 429: 515-26. doi:10.1042/ BJ20091649.

11. Zhang $Q$, Shen M, Ding M, Shen D, Ding F. The neuroprotective action of pyrroloquinoline quinone against glutamate-induced apoptosis in hippocampal neurons is mediated through the activation of PI3K/Akt pathway. Toxicology and applied pharmacology. 2011; 252: 62-72. doi:10.1016/j.taap.2011.02.006.

12. Toimela T, Tahti H, Ylikomi T. Comparison of an automated pattern analysis machine vision time-lapse system with traditional endpoint measurements in the analysis of cell growth and cytotoxicity. Alternatives to laboratory animals : ATLA. 2008; 36: 313-25.

13. Zhang $\mathrm{P}, \mathrm{Xu} \mathrm{Y}$, Sun J, Li X, Wang L, Jin L. Protection of pyrroloquinoline quinone against methylmercury-induced neurotoxicity via reducing oxidative stress. Free radical research. 2009; 43: 224-33. doi:10.1080/10715760802677348.

14. Kumazawa T, Hiwasa T, Takiguchi M, Suzuki O, Sato K. Activation of Ras signaling pathways by pyrroloquinoline quinone in NIH3T3 mouse fibroblasts. International journal of molecular medicine. 2007; 19: 765-70.

15. Kimura K, Takada M, Ishii T, Tsuji-Naito K, Akagawa M. Pyrroloquinoline quinone stimulates epithelial cell proliferation by activating epidermal growth factor receptor through redox cycling. Free radical biology \& medicine. 2012; 53: 1239-51. doi:10.1016/j.freeradbiomed.2012.07.015.

16. Simon HU, Haj-Yehia A, Levi-Schaffer F. Role of reactive oxygen species (ROS) in apoptosis induction. Apoptosis : an international journal on programmed cell death. 2000; 5: 415-8.

17. Pelicano H, Feng L, Zhou Y, Carew JS, Hileman EO, Plunkett W, et al. Inhibition of mitochondrial respiration: a novel strategy to enhance drug-induced apoptosis in human leukemia cells by a reactive oxygen species-mediated mechanism. The Journal of biological chemistry. 2003; 278: 37832-9. doi:10.1074/jbc.M301546200.

18. Bras M, Queenan B, Susin SA. Programmed cell death via mitochondria: different modes of dying. Biochemistry Biokhimiia. 2005; 70: 231-9.

19. Vander Heiden MG, Chandel NS, Schumacker PT, Thompson CB. Bcl-xL prevents cell death following growth factor withdrawal by facilitating mitochondrial ATP/ADP exchange. Molecular cell. 1999; 3: 159-67.

20. Lowe SW, Cepero E, Evan G. Intrinsic tumour suppression. Nature. 2004; 432: 307-15. doi:10.1038/nature03098.

21. Marchetti P, Castedo M, Susin SA, Zamzami N, Hirsch T, Macho A, et al. Mitochondrial permeability transition is a central coordinating event of apoptosis. The Journal of experimental medicine. 1996; 184: 1155-60.

22. Singh N, Nambiar D, Kale RK, Singh RP. Usnic Acid inhibits growth and induces cell cycle arrest and apoptosis in human lung carcinoma a549 cells. Nutrition and cancer. 2013; 65 Suppl 1: 36-43. doi:10.1080/01635581.2013.785007.

23. Tung YT, Chen HL, Lee CY, Chou YC, Lee PY, Tsai HC, et al. Active Component of Danshen (Salvia miltiorrhiza Bunge), Tanshinone I, Attenuates Lung Tumorigenesis via Inhibitions of VEGF, Cyclin A, and Cyclin B Expressions. Evidence-based complementary and alternative medicine eCAM. 2013; 2013: 319247. doi:10.1155/2013/319247.

24. Antonoff MB, Chugh R, Borja-Cacho D, Dudeja V, Clawson KA, Skube SJ, et al. Triptolide therapy for neuroblastoma decreases cell viability in vitro and inhibits tumor growth in vivo. Surgery. 2009; 146: 282-90. doi:10.1016/j.surg.2009.04.023.

25. Chen YH, Yeh CW, Lo HC, Su SL, Hseu YC, Hsu LS. Generation of reactive oxygen species mediates butein-induced apoptosis in neuroblastoma cells. Oncology reports. 2012; 27: 1233-7. doi:10.3892/or.2012.1632.

26. Korsmeyer SJ. BCL-2 gene family and the regulation of programmed cell death. Cancer research. 1999; 59: 1693s-700s.

27. Luo X, Budihardjo I, Zou H, Slaughter C, Wang X. Bid, a Bcl2 interacting protein, mediates cytochrome $\mathrm{c}$ release from mitochondria in response to activation of cell surface death receptors. Cell. 1998; 94: 481-90.

28. Chipuk JE, Moldoveanu T, Llambi F, Parsons MJ, Green DR. The BCL-2 family reunion. Molecular cell. 2010; 37: 299-310. doi:10.1016/j.molcel.2010.01.025.

29. Rolland SG, Conradt B. New role of the BCL2 family of proteins in the regulation of mitochondrial dynamics. Current opinion in cell biology. 2010; 22: 852-8. doi:10.1016/j.ceb.2010.07.014.

30. Janicke RU, Sprengart ML, Wati MR, Porter AG. Caspase-3 is required for DNA fragmentation and morphological changes associated with apoptosis. The Journal of biological chemistry. 1998; 273: 9357-60. 
31. Singh T, Sharma SD, Katiyar SK. Grape proanthocyanidins induce apoptosis by loss of mitochondrial membrane potential of human non-small cell lung cancer cells in vitro and in vivo. PloS one. 2011; 6: e27444. doi:10.1371/journal.pone.0027444.

32. Jung KH, Noh JH, Kim JK, Eun JW, Bae HJ, Xie HJ, et al. HDAC2 overexpression confers oncogenic potential to human lung cancer cells by deregulating expression of apoptosis and cell cycle proteins. Journal of cellular biochemistry. 2012; 113: 2167-77. doi:10.1002/jcb.24090.

33. Dhanasekaran DN, Johnson GL. MAPKs: function, regulation, role in cancer and therapeutic targeting. Oncogene. 2007; 26: 3097-9. doi:10.1038/sj.onc.1210395.

34. Hu M, Du Q, Vancurova I, Lin X, Miller EJ, Simms HH, et al. Proapoptotic effect of curcumin on human neutrophils: activation of the p38 mitogen-activated protein kinase pathway. Critical care medicine. 2005; 33: 2571-8.

35. Zarubin T, Han J. Activation and signaling of the p38 MAP kinase pathway. Cell research. 2005; 15: 11-8. doi:10.1038/sj.cr.7290257.

36. Owens TW, Valentijn AJ, Upton JP, Keeble J, Zhang L, Lindsay J, et al. Apoptosis commitment and activation of mitochondrial Bax during anoikis is regulated by p38MAPK. Cell death and differentiation. 2009; 16: 1551-62. doi:10.1038/cdd.2009.102.

37. Van Laethem A, Van Kelst S, Lippens S, Declercq W, Vandenabeele P, Janssens $\mathrm{S}$, et al. Activation of p38 MAPK is required for Bax translocation to mitochondria, cytochrome $\mathrm{c}$ release and apoptosis induced by UVB irradiation in human keratinocytes. FASEB journal : official publication of the Federation of American Societies for Experimental Biology. 2004; 18: 1946-8. doi:10.1096/fj.04-2285fje.

38. Vermeulen L, Vanden Berghe W, Beck IM, De Bosscher K, Haegeman G. The versatile role of MSKs in transcriptional regulation. Trends in biochemical sciences. 2009; 34: 311-8. doi:10.1016/j.tibs.2009.02.007.

39. Kim BJ, Ryu SW, Song BJ. JNK- and p38 kinase-mediated phosphorylation of Bax leads to its activation and mitochondrial translocation and to apoptosis of human hepatoma HepG2 cells. The Journal of biological chemistry. 2006; 281: 21256-65. doi:10.1074/jbc.M510644200.

40. Johnson GL, Lapadat R. Mitogen-activated protein kinase pathways mediated by ERK, JNK, and p38 protein kinases. Science. 2002; 298: 1911-2. doi:10.1126/science.1072682.

41. McCubrey JA, Steelman LS, Chappell WH, Abrams SL, Wong EW, Chang F, et al. Roles of the Raf/MEK/ERK pathway in cell growth, malignant transformation and drug resistance. Biochimica et biophysica acta. 2007; 1773: 1263-84. doi:10.1016/j.bbamcr.2006.10.001.

42. Meloche S, Pouyssegur J. The ERK1/2 mitogen-activated protein kinase pathway as a master regulator of the G1- to S-phase transition. Oncogene. 2007; 26: 3227-39. doi:10.1038/sj.onc.1210414.

43. He B, Liu SQ, Li HH. [The extracellular signal-regulated kinase was promoted by pyrroloquinoline quinine in cultured Schwann cells]. Zhonghua zheng xing wai ke za zhi = Zhonghua zhengxing waike zazhi = Chinese journal of plastic surgery. 2010; 26: 444-7.

44. Gotfryd K, Skladchikova G, Lepekhin EA, Berezin V, Bock E, Walmod PS. Cell type-specific anti-cancer properties of valproic acid: independent effects on HDAC activity and Erk1/2 phosphorylation. BMC cancer. 2010; 10: 383. doi:10.1186/1471-2407-10-383.

45. Kim JK, Choi JW, Lim S, Kwon O, Seo JK, Ryu SH, et al. Phospholipase C-eta1 is activated by intracellular $\mathrm{Ca}(2+)$ mobilization and enhances GPCRs/PLC/Ca(2+) signaling. Cellular signalling. 2011; 23: 1022-9. doi:10.1016/j.cellsig.2011.01.017.

46. Sidiropoulou E, Sachana M, Flaskos J, Harris W, Hargreaves AJ, Woldehiwet $Z$. Fipronil interferes with the differentiation of mouse N2a neuroblastoma cells. Toxicology letters. 2011; 201: 86-91. doi:10.1016/j.toxlet.2010.12.009. 